\title{
Qualitative and Semiquantitative Determination of Bromine in Hybrid Hydroxyurethanes-Poly(dimethylsiloxane) Films Containing Phosphotungstates ([PW $\left.{ }_{12} \mathrm{O}_{40}\right]^{3-}$ )
}

\author{
Orlando Elguera Ysnaga \\ Institute of Chemistry of Sao Carlos, University of Sao Paulo (IQSC-USP), Sao Carlos-SP, Brazil
}

Email address:

orlandoelguera@gmail.com

To cite this article:

Orlando Elguera Ysnaga. Qualitative and Semiquantitative Determination of Bromine in Hybrid Hydroxyurethanes-Poly(dimethylsiloxane) Films Containing Phosphotungstates ([$\left.\left[\mathrm{PW}_{12} \mathrm{O}_{40}\right]^{3-}\right)$. Engineering Physics. Vol. 4, No. 2, 2020, pp. 19-36. doi: 10.11648/j.ep.20200402.11

Received: December 14, 2020; Accepted: December 22, 2020; Published: December 31, 2020

\begin{abstract}
In this study, the complex hybrid materials based on hybrid poly(dimethylsiloxane)-derived hydroxyurethanes films (PDMSUr-PWA) containing phosphotungstic acid $\left(\mathrm{H}_{3} \mathrm{PW}_{12} \mathrm{O}_{40} / \mathrm{PWA}\right)$ and Bromine were analyzed by laboratory XRF (EDXRF,

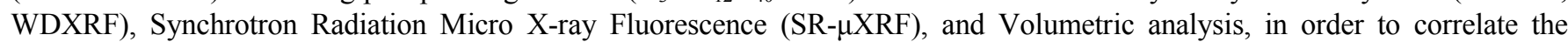
distribution patterns and composition of Bromine with their respective properties and potential applications. Recently, the characterization and analysis of PDMSUr-PWA films (without consider Bromine) was reported in order to correlate structure, compositions and properties. SR- $\mu$ XRF maps provide indicatives of the possible inter-elemental interactions Bromine-Silicon-Tungsten. There is segregation of Bromine at surface and through the thickness of PDMSUr-PWA films. These films possess hydrophobicity and non-hygroscopic properties, which makes potential candidates for high-performance adhesives, corrosion-resistant coatings of steel and titanium alloys surfaces in different media. The presence of Bromine (element provided from tetraethylammonium bromide in previous steps of elaboration of PDMSUr-PWA films) could contribute with their corresponding adhesive, thermal-insulator, and anti-corrosive properties. Functional materials as PDMSUr-PWA films present easy processing, excellent toughness and durability. Nowadays, Polyurethane (PU) coatings are very useful in many sectors due to their excellent mechanical properties. Nonetheless, one limitation is their thermal stability, which can be improved by insertion of poly(dimethylsiloxane) (PDMS) segments. The interesting properties of PDMS are of significance for applications as adhesives and at the aerospace industry. The films containing 1\%, 35\%, 40-50\% PWA are candidates as anticorrosive coatings and as inert materials under the presence of polar chemical reagents, based on the significant Bromine presence at surface. The films containing $25 \%$ and $55 \%$ PWA would be suitable for thermal insulators, based on the significant Bromine presence at thickness. PDMSUr-PWA films can constitute systems for the storage of energy based on the synergy of their potential applications as Proton exchange membrane fuel cells (PEMFCs) and also as $\mathrm{H}_{2}-\mathrm{Br}_{2}$ multiple micro-fuel cells. PEMFCs have great attention in scientific and industrial fields based on energetic and environmental aspects mainly. PEMFCs based on PDMSUr-PWA films could exhibit high chemical and mechanical stabilities. The hydrogen bromine $\left(\mathrm{H}_{2}-\mathrm{Br}_{2}\right)$ electrochemical systems constitute promising candidates as generation and storage devices of energy due to their high energy capacities and conversion efficiencies, as also their low costs. More in depth studies are necessary in order to analyze the different chemical forms of Bromine present (atomic, ionic and/or molecular) in the three-dimensional network constituted by silicates and phosphotungstates, as also the characterization of their local chemical and electrochemical environment.
\end{abstract}

Keywords: PDMSUr-PWA Films, Bromine, SR- $\mu$ XRF, Hybrid Materials, Fuel Cells

\section{Introduction}

Functional materials present easy processing, excellent toughness and durability. Hybrid (organic-inorganic entities mixed at molecular level) materials meet these conditions, which are classified according to the interactions between organic and inorganic parts as Class-I and Class-II. In Class-I predominates hydrogen bonds, and non-covalent, electrostatic and van der Waals interactions. On another hand, in Class-II predominates the strong covalent bonds, involving silanization, imidization and esterification reactions 
commonly [1, 2]. Polyurethane (PU) coatings are of paramount importance in many sectors due to their excellent mechanical properties. However, their poor thermal stability limits applications at high temperatures. In order to overcome this limitation, PU have to be modified by means of introducing poly(dimethylsiloxane) (PDMS) segments in the PU backbone. PDMS exhibits interesting properties such as high thermal and oxidative stability, low glass transition temperature $\left(\mathrm{T}_{\mathrm{g}}\right)$, high permeability to many gases, low surface tension, good antifouling properties, very good UV stability, and biocompatibility. The low $T_{g}$ of poly(dimethylsiloxane) resins makes them potential candidates for adhesives and applications at the aerospace industry. Nevertheless, the poor mechanical properties, abrasion resistance, and insufficient thermal stability of PDMS limit its application in many fields. This thermal stability could be improved by means of the incorporation of silica nanoparticles and/or cross-linking. Cross-linked PDMS networks suffer from severe swelling upon contact with, especially non-polar, organic solvents, thereby drastically reducing its performance [3-7]. It was hypothesized that one way to improve the fire resistance of polyurethane without significantly sacrificing the mechanical properties was to utilize PDMS as a reactive co-soft segment. However, PDMS is incompatible with PU, based on its low parameter of solubility $\left(14,9 \mathrm{~J}^{1 / 2} \cdot \mathrm{cm}^{-3 / 2}\right)$ and by the poor interaction between them (PDMS: non-polar nature/PU: polar nature), leading to the creation of a polymer phase thermodynamically and mechanically incompatible. This incompatibility generates phase segregation in the polyurethane (PU) morphology. For this reason, reinforcing agents, compounds that forming cross-linked bonds/structures, are needed in the PDMS/PU system in order to combine their properties [3,4]. The study published by Vega et al [8] about of polyurethanes without silica indicates that increase of $\mathrm{NCO} / \mathrm{OH}$ ratio in turn increases the degree of phase segregation, due to the effect of repulsion that exists between the polar hard segments of polyurethane and non-polar chains of polyol. With the addition of hydrophilic silica to polyurethane the degree of phase separation is reduced, indicating a possible interaction of silica and silanol groups (by means of hydrogen bonds) with the polymer $[8,9]$. A way to introduce PDMS segments and silica contents is initially to prepare cyclic carbonates from an epoxydic reagent bearing PDMS, as published by our research group [10-12]. Insertion of PDMS and silica terminal groups in a unique oligomeric backbone makes possible to obtain a hybrid polyurethane (PDMSUr) with valuable physical-chemical properties such as thermal resistance, hardness, corrosion protection, adhesion in glasses, besides others. PDMS-Silica Hybrids, denoted as Ormosil (organically modified silicates) consist of nm-sized silica clusters and PDMS chains [3]. Aminosilanes, such as 3-aminopropyltriethoxysilane (APTES) can play a role in opening the cyclic carbonate ring to form urethane bonds allowing the production of a Class II hybrid material by the Sol-gel process. Sol-gel chemistry constitutes a rapid method for fabrication of ceramics, glasses, and thin films [2]. In this process, the condensation of silanol groups generate regions of Organically Modified Silicates (ORMOSIL), which constitute a host network for polyoxometalates, such as phosphotungstic acid (PWA), which acts as reinforcing agent inside the hybrid material through crosslinks. Sol-Gel reaction allows a better distribution of PWAs and control for the size of the particles. PWA is used in the elaboration of these functional hybrid materials, because provide additional properties, such as electrical and mechanical functionalities [1, 9-12]. The existence of electrostatic forces between silicates and PWA would enable the production of a Class I hybrid material also. Thus, these hybrid materials can exhibit features of both classes. Protons contained in PWAs, the counterions generated at their surroundings, in addition to their remarkable properties as proton conductivity, thermal stability and water-retention capability make PWAs useful as multifunctional proton conductors [1]. PDMSUr is also suitable for use as anti-corrosive coatings, in which an important feature to consider is the hydrophobicity. This feature prevents the corrosion and is inherent in PDMS segments and dependent on the functional group $\left(-\mathrm{CH}_{3},-\mathrm{CF}_{3}\right.$, $\left.-\mathrm{OCH}_{3},-\mathrm{CO}_{2} \mathrm{CH}_{3},-\mathrm{Br}\right)$ attached to the silicone chain. On another hand, the presence of polar functional groups such as $-\mathrm{OH},-\mathrm{NH}_{2}$ or $-\mathrm{COOH}$ would increase the hydrogen bonding interactions, thus the polar characteristics of the surface energy [10-12]. The hydrophobicity constitutes a physical barrier in order to avoid corrosion of metals in physiological medium, which makes PDMSUr hybrid coatings good candidates for use as orthopedic or dental implants. Also, some of these films showed transparency that would enable their use at medical and electrical applications [11-13]. Among the various challenges of electrochemistry that hybrid materials, like PDMSUr-PWA films, can resolve is satisfy the demand for materials with remarkable proton conductivity at elevated temperatures, for use as proton-exchange membrane for fuel cells (PEMFCs) $[14,15]$. Due to the high-demand for clean energy devices, fuel cells have attracted the attention in academic and industrial communities. Proton exchange membrane fuel cells (PEMFCs) have been extensively studied due to their high-power densities and low environmental impacts $[14,15]$. Fuel cells are superior than fuel sources in energetic and environmental aspects. Proton exchange membrane (PEM), are among the different types of fuel cells, serve as conductors for protons and a barrier for fuels. PEMs based on Class-II Hybrids materials exhibit good conductivity as also mechanical resistance and chemical stability [1]. Hydrated PWA is highly soluble in water, being well stabilized in the presence of inorganic networks, such as silicate network, through strong Coulombic interactions ${ }^{9}$. PWA present two key features for the fabrication of PEMs: 1) The hydronium ion forms $\left(\mathrm{H}_{3} \mathrm{O}^{+}, \mathrm{H}_{5} \mathrm{O}_{2}{ }^{+}\right.$and $\left.\mathrm{H}_{9} \mathrm{O}_{4}{ }^{+}\right)$of protons, 2) The Keggin-type structure that contain long and continuous channels available for proton transport. From Heteropoly acids (HPAs) immobilized, especially PWA (e.g in PDMSUr matrix), can be made PEMs with high proton conductivities and performances at different temperature levels [10, 12, 14, 15]. For this reason, membranes based on composite materials containing HPAs, immobilized in PDMS/PDMSUr matrices, can constitute proton conductive materials for 
operation at elevated temperatures. It is crucial for PEMs based on PWA the understanding of mechanisms for proton transport (facilitated by water molecules from heteropolyanion), and thus, of their conductivity also for the development of fuel cells $[14,15]$. For PEMs based on PWA contained in mesoporous silica matrix structure, the dependency of proton conductivity with PWA content $<10$ $\mathrm{wt} / \mathrm{wt} \%$ is very significant. There are indicatives, from Durability test and ${ }^{31} \mathrm{P}$ MAS NMR characterization about the stability of PWA ions inside and at surface of these matrices respectively [1]. This ionic stability mentioned above is also present in the PDMSUr-PWA films, based from FTMIR results, which besides give indicatives about the interactions among the PWA ions with silicate regions, through of silanol groups $\left(\equiv \mathrm{SiOH}_{2}{ }^{+}\right)$mainly, and with the organic matrix of PDMSUr [10]. HPAs containing protons, as also counter-cations, have been used in the fabrication of hybrid PEMs [14, 15]. In PDMSUr-PWA films, the silanol groups can act as counter-ions for PWA ions, producing species e.g. $\left.\left(\equiv \mathrm{SiOH}_{2}^{+}\right)_{\mathrm{x}}\left(\mathrm{H}_{2} \mathrm{PW}_{12} \mathrm{O}_{40}\right)^{-}\right)_{\text {y }}[9,11]$.

During processing of the PDMSUr-PWA films, more exactly for the elaboration of their precursor the bis-cyclic carbonate PDMS-derivative (CCPDMS), is used the Tetraethylammonium Bromide (TEAB, $\left(\mathrm{C}_{4} \mathrm{H}_{9}\right)_{4}$. N. Br). The subsequent purification process, by solvent and water extraction, could remove $73.3 \%$ of Bromine (value determined by X-ray fluorescence analysis) from the final mixture of CCPDMS. The rest of Bromine (as atomic, ionic or molecular forms) not removed $(26.7 \%)$ possibly could form a compound derived of PDMS (stoichiometric and/or non-stoichiometric) and/or is distributed through or at surroundings of the interstices of CCPDMS structure $[9,10]$. For this reason, is important the knowledge, in special by means of a non-destructive method of analysis, of the distribution and composition of Bromine in PDMSUr-PWA films in order to correlate with their thermal, electrical, and mechanical properties, being one of their aims the application as Fuel Cells based on Hydrogen-Bromine Flow Batteries.

Availability of low-cost, high-capacity energy storage technology change currently the energy landscape. The large interest in renewable energy sources (sun and wind) during recent years has raised the demand for large-scale, low-cost and durable electrical energy generation and storage solutions. Electrochemical systems (batteries and fuel cells) are promising candidates for these purposes. The hydrogen bromine $\left(\mathrm{H}_{2}-\mathrm{Br}_{2}\right)$ fuel cell systems present as advantages: high energy capacities and conversion efficiencies, power density capabilities and low costs [16]. In these cells, the electrolysis of hydrobromic acid ( $\mathrm{HBr}$ ) is utilized for storing the electric energy: $2 \mathrm{HBr}+$ electrical energy $\leftrightarrow \mathrm{H}_{2}+\mathrm{Br}_{2}$. In the $\mathrm{HBr}$ electrolysis, Hydrogen $\left(\mathrm{H}_{2}\right)$ and Bromine $\left(\mathrm{Br}_{2}\right)$ are generated and stored separately. When needed, they are converted again into hydrobromic acid $\left(\mathrm{HBr}_{(\mathrm{aq})}\right)$ in order to obtain electric energy, specifically, in a fuel cell reaction [17] Large-scale electrochemical devices based on the use hydrogen and bromine offer several attractive features. Bromine is inexpensive, readily available, and abundant. In addition, the Chemical reaction between them occurs extremely rapidly [18]. The high energy densities of these systems, make them candidates for space power applications. The advantage the hydrogen-bromine system is the high solubility of bromine in hydrobromic acid. The energy is stored in the form of bromine in the electrolyte reservoir and as hydrogen gas in the hydrogen reservoir [19]. The hydrogen-bromine fuel cell system can be operated in the acid or alkaline modes. The performance of the $\mathrm{H}_{2}-\mathrm{Br}_{2}$ fuel cell could be improved by using higher reactant concentrations, higher operating temperatures, more conductive membranes. However, the performance is currently limited by the low ionic conductivity of the membranes, which is attributed to the slow ionic diffusivity $[20,21]$. Flow batteries, based on the choice hydrogen and bromine as active materials lead to several advantages, between them that generates high-power density $\left[\mathrm{W} / \mathrm{m}^{2}\right]$ and energy density $\left(\mathrm{kWh} / \mathrm{m}^{3}\right)$. The formation of hydrogen bromide in aqueous phase $\left(\mathrm{HBr}_{(\mathrm{aq})}\right)$ from $\mathrm{H}_{2}$ and $\mathrm{Br}_{2}$, and the dissociation of hydrogen bromide in $\mathrm{H}$ and $\mathrm{Br}$, constituting a reversible fuel cell with electric efficiencies up to $70 \%$ for current densities between 150-225 mA.cm ${ }^{-2}$. The electrolyte ( $\mathrm{HBr} / \mathrm{Br}$ solution) and hydrogen $\left(\mathrm{H}_{2}\right)$ circuits are separated by a proton-conductive membrane. Membrane thickness is closely related to their acid permeability and polarization resistance. The transport properties of the membrane are related to water content of the membrane [22-25]. It would be interesting to know the influence of Bromine in the proton conduction of this multifunctional hybrid nanomaterials system. For fuel cells, the ideal voltage is $1.2 \mathrm{~V}$ at current densities correspond to orders of few $\mathrm{A} / \mathrm{cm}^{2}$. In the case of PDMSUr-PWA films, the range of current densities for the voltage mentioned above is $10^{-7}-10^{-5} \mathrm{~A} / \mathrm{cm}^{2}[9,12]$. Thus, for each $\mathrm{cm}^{2}$ the requirement of current for these films could be is much times lower than conventional fuel cells.

The aim of this study is the development of analysis methodology for Bromine in PDMSUr-PWA films without certified reference material. The quantitative-semi-quantitative determination of Bromine presents an analytical challenge, since it cannot be performed by diverse analysis methods (AAS, ICP-OES, ICP-MS, among others). Unlike what was published recently for these films, Neutron Activation Analysis (NAA) could not be applied directly (may be use as an approximation from a standard method) because due to the high concentration of Tungsten there is overlap of peaks (due to $\mathrm{W}$ peaks or due to the corresponding background noise) [26]. For these reasons, it was performed Volumetric analysis that attains the bulk determination of Bromine. Nonetheless, this reference analytic method does not allow the analysis "in-situ" of this element, reason for what was chosen X-ray Fluorescence (XRF), in order to determine Bromine at depth of few hundreds of micrometers, and Synchrotron Radiation Micro X-ray Fluorescence (SR- $\mu \mathrm{XRF}$ ) for mapping of the distribution of this element in these films and thus, can correlate their atomic patterns, composition and properties. composition and properties. Different modes of XRF (EDXRF, WDXRF, TXRF, $\mu$ XRF) constitutes a very useful method of analysis in order to determinate traces of Bromine [27-36]. 
Energy Dispersive X-ray Fluorescence (EDXRF) measurements were performed for traces analysis of Bromine in soils, sediments, and other matrices [27, 29]. Wavelength Dispersive X-ray Fluorescence (WDXRF) analyses has been performed in order to determinate Bromine in different matrices [30, 31]. Pashkova et al applied Wavelength Dispersive X-ray Fluorescence (WDXRF) and Total Reflection $\mathrm{X}$-ray Fluorescence (TXRF) methods in combination for the determination of Bromine in sediment matrices [32]. Leri et al performed Micro-XRF analysis for mapping of elemental distribution of Bromine in enriched-soils plants samples [33]. Mantouvalou et al used 2D- $\mu$ XRF and 3D- $\mu$ XRF analysis for determination of Bromine ${ }^{34}$. Micro X-ray Fluorescence $(\mu \mathrm{XRF})$ has been applied in the analysis of brominated flame retardants (BFRs) [35]. The experimental setup used with SR-XRF allowed nondestructive elemental analysis with high sensitivity, achieving detection limits lower than $1 \mathrm{ppm}$. Synchrotron Radiation Micro X-ray Fluorescence (SR- $\mu$ XRF) measurements enables determination of Bromine traces (0.39-1.5 mg. $\left.\mathrm{Kg}^{-1}\right)$ at vitreous matrices [36].

\section{Material and Methods for the Preparation of Films}

\subsection{Materials}

All reagents used to synthesize the precursor cyclic carbonate PDMS-derived, here labelled as CCPDMS, are described in references $[10,11]$. To the obtaining of polyhydroxyurethanes PDMS-derived (PDMSUr), the following reactants were used: purified CCPDMS, 3-aminopropyltriethoxysilane (APTES, >98\%, Sigma Aldrich), 3-aminomethyl-3,5,5-trimethylcyclohexylamine (IPDA, $>99 \%$, mixture of cis and trans, Sigma Aldrich), dimethylacetamide (DMAc, 99,5\%, Vetec), nitrogen $\left(\mathrm{N}_{2},>\right.$ 99\%, White Martins), phosphotungstic acid hydrate (PWA, Sigma Aldrich) dried at $60^{\circ} \mathrm{C}$ overnight.

\subsection{Method of Preparation of Films}

The synthesis of the precursors CCPDMS followed the procedure described by Aguiar et al ${ }^{3}$. After purification of

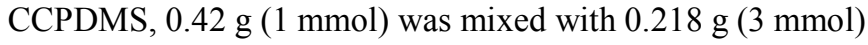
of APTES in a vial previously purged with $\mathrm{N}_{2}$. The reaction mixture remained under stirring for 40 minutes at $70^{\circ} \mathrm{C}$. Finally, the samples were dissolved in $2 \mathrm{~mL}$ of DMAc were dispersed into the hybrid polyurethane matrix and stirred for $24 \mathrm{~h}$ at $60^{\circ} \mathrm{C}[10-11]$.

\section{Methods of Analysis}

\subsection{X-ray Fluorescence Spectrometry of Laboratory (XRF)}

\subsubsection{Energy Dispersive X-ray Fluorescence Spectrometry (EDXRF)}

EDXRF measurements for Bromine contained in the PDMSUr-PWA samples were performed by two different Energy Dispersive X-ray Fluorescence (EDXRF) spectrometers:
1. Minipal-4 Model PW4025 PANalytical benchtop EDXRF spectrometer, equipped with 9W Rh X-ray tube and SDD detector (resolution $145 \mathrm{eV}$ ). Experiments were done under Helium atmosphere; the acquisition time per sample was $450 \mathrm{seg}$. It was used Omnian software (PANalytical, Netherlands) in order to perform the semi-quantitative determination. They were performed ten measurements per sample.

2. MINI X Model X-123 SDD Amptek ${ }^{\circledR}$ Portable EDXRF spectrometer, equipped with $2.5 \mathrm{~W}$ X-ray tube with $\mathrm{Ag}$ target and high-performance Si Drift detector $\left(25 \mathrm{~mm}^{2} \mathrm{x}\right.$ $500 \mu \mathrm{m})\left(\right.$ Si Drift $25 \mathrm{~mm}^{2}$ x $\left.500 \mu \mathrm{m} / 0.5 \mathrm{mil}\right)$ with Beryllium window (1.5"). Each sample was irradiated for $300 \mathrm{~s}$.

For Bromine determination by EDXRF the chosen line was $\mathrm{Br}_{\alpha}(11.924 \mathrm{KeV})$.

\subsubsection{Wavelength Dispersive X-ray Fluorescence Spectrometry (WDXRF)}

Measurements for Bromine were performed at the WDXRF Rigaku RIX 3000 spectrometer equipped with one $3 \mathrm{~kW} \mathrm{Rh}$ X-ray tube, analyzer crystal LiF 200, and scintillation counter detector (SC) and $20 \mathrm{~mm} 2$ irradiation area. Experiments were done under Helium atmosphere; the acquisition time per sample was $45 \mathrm{~min}$. For Bromine determination, the XRF line chosen was $\mathrm{Br}_{\alpha} \mathrm{K}_{\alpha}\left(29.941^{\circ}\right)$. They were performed three measurements per sample.

\subsection{Synchrotron Radiation Micro X-ray Fluorescence $(S R-\mu X R F)$}

Bromine in PDMSUr-PWA films was analyzed via Synchrotron Radiation Micro X-ray Fluorescence (SR- $\mu \mathrm{XRF}$ ), which measurements were performed at the D09B $\left(15^{\circ}\right)$ bending-magnet XRF beamline of the Brazilian Synchrotron Light Source (LNLS, Campinas-Brazil) ${ }^{37}$. The experiments were done in air atmosphere at atmospheric pressure, choosing the XRF line $\mathrm{Br}_{\alpha} \mathrm{K}_{\alpha}(11.924 \mathrm{KeV})$. The experimental setup for SR- $\mu \mathrm{XRF}$ analysis included:

I. The $1.4 \mathrm{GeV}$ Source (storage ring) provides a polychromatic X-ray beam, which photon flux ranging from $3.9 \times 10^{10}$ to $2.31 \times 10^{11}$ photons $/ \mathrm{sec}$, with an energy ranging up to $16 \mathrm{keV}$.

II. The Micro-focusing system, consisted in: a rotation/ high-precision $x-y$ translation stage of the sample driven by stepping motors in order to focalize; a sample chamber that can be evacuated, in order to avoid the attenuation of X-rays and to suppress the scattered radiation by the air; two non-plane mirrors arranged at Kirkpatrick-Baez (KB) configuration; and a microscope, in order to identify the sample region to be analyzed. In this setup, the elliptical microbeam had the dimensions $18 \mu \mathrm{m}$ (major axis) x $9 \mu \mathrm{m}$ (minor axis) approximately, with a working distance of about $0.1 \mathrm{~m}$ [37].

III. The Detection system, consisted in a CANBERRA Si (Li) X-ray detector model SL30165, with resolution of $165 \mathrm{eV}$ at $5.9 \mathrm{keV}$, operating in transmission geometry at Energy Dispersive mode. This detector was cooled by 
$\mathrm{N}_{2}$ (1), in order to reduce the heat load [37].

IV. SR- $\mu$ XRF maps were processed, collecting a number between 400-420 sampling points (each point depicts to one XRF spectrum) scanned at zig-zag mode. The time of acquisition of SR- $\mu \mathrm{XRF}$ analysis by point was 5 seconds. The raw spectral data were analyzed using the Readcnfmca v2.0 program (developed at the LNLS XRF Beamline) and PyMCA X-ray Fluorescence version 4.4 program [38, 39] (developed by the Software Group of the European Synchrotron Radiation Facility-ESRF), in order to extract the $\mu \mathrm{XRF}$ intensities for each point measurement and process them into elemental maps respectively. The pixel size of the SR- $\mu$ XRF maps was $26 \mu \mathrm{m}$ [40]. Acquired XRF data set at LNLS were processed by PyMCA 4.4 software, based on the Fundamental Parameter Method (FP).

$\mathrm{V}$. The ratios of concentrations for Bromine $(\mathrm{Br})$ within ormosil films were calculated from the mass fractions obtained by the PyMCA 4.4, using the procedure for semi-quantitative determination $[38,39]$ based on the Fundamental Parameters Method (FP). For this procedure were used the correspondent instrumental parameters to the D09B-XRF line of LNLS-Campinas-Brazil [37]. See
Section S6 at the Supplemental Material.

\subsection{Reference Method for Determination of Bromine (Volumetric Analysis Using the Schöniger Flask Method)}

$15 \mathrm{mg}$ of sample are weighed and burned in a hermetically sealed Schöniger flask containing $0.1 \mathrm{~N} \mathrm{NaOH}$ solution. The bottle is kept closed for a minimum of 3 hours to ensure that all Br-formed is absorbed into the solution. The resulting solution is acidified with $0.1 \mathrm{~N}^{\mathrm{HNO}_{3}}$ (in the presence of bromophenol blue) and titrated with $0.01 \mathrm{~N}$ standard $\mathrm{Hg}$ $\left(\mathrm{NO}_{3}\right)_{2}$ solution using diphenylcarbazone as an indicator. The molar ratio of the $\mathrm{HgBr}_{2}$ precipitation reaction is used to calculate the percentage of $\mathrm{Br}$ in the sample [41].

\subsection{Reference Materials}

SR- $\mu$ XRF: the reference materials used were XRF Calibration Standards (99.9\% pure or better) of Zinc Telluride $(\mathrm{ZnTe})$ with areal density $=46.1 \mu \mathrm{g} / \mathrm{cm}^{2}( \pm 5 \%)$ provided by the Micromatter Company under the form of thin films on Mylar ${ }^{\circledR}$ substrate.

http://www.micromatter.com/XRFCalibrationStandards.aspx.

Bromine-Silicon-Tungsten Concentrations Ratio vs. \%PWA for PDMSUr-PWA samples

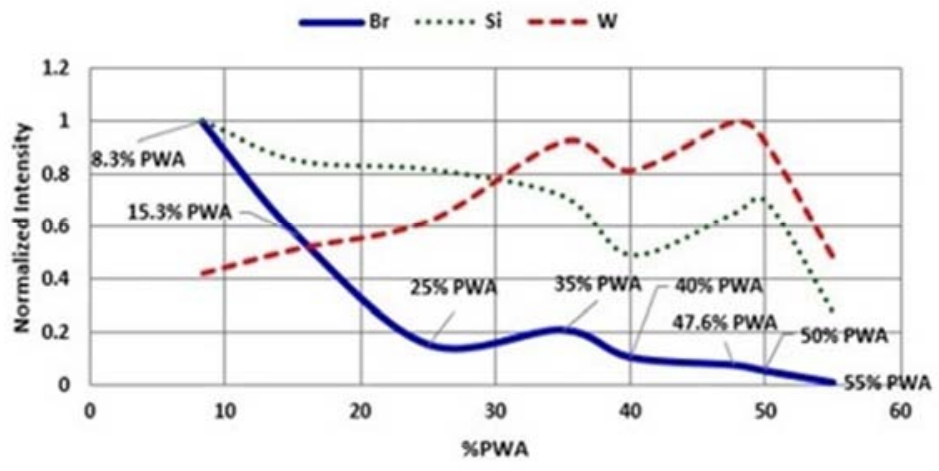

Bromine-Silicon-Tungsten Concentrations Ratio vs. \%PWA for PDMSUr-PWA samples

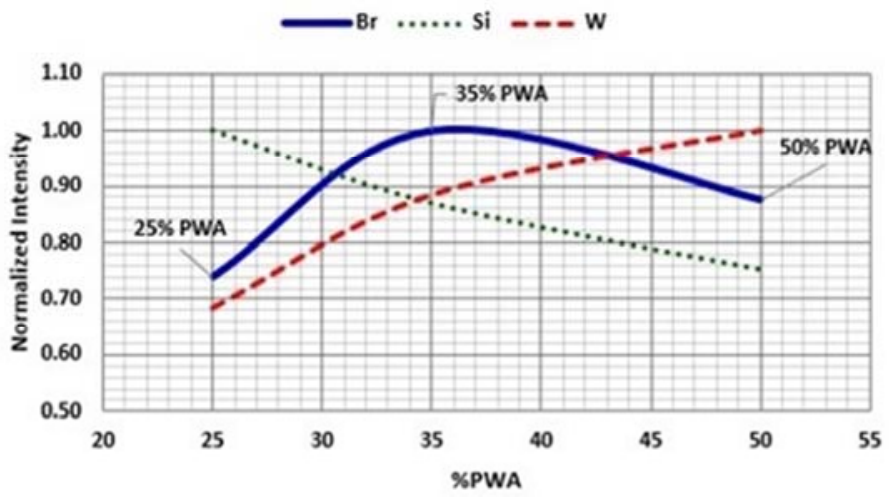

Figure 1. Figure 1a (top). Bromine (solid blue line), Silicon (dotted green line) and Tungsten (dashed red line) intensities ratios as function of \% PWA for PDMSUr-PWA samples obtained by EDXRF Amptek spectrometer. Figure 1 b (bottom)- Bromine (solid blue line), Silicon (dotted green line) and Tungsten (dashed red line) intensities ratios as function of \% PWA for PDMSUr-PWA samples obtained by WDXRF analysis. 


\begin{tabular}{lll}
\hline Characterization Technique / Method of analysis & This technique/method of analysis allows for PDMSUr-PWA films. \\
\hline XRF Analysis in situ of PWA & EDXRF & $\begin{array}{l}\text { Fast and precise determination of major and minor elements. } \\
\text { Determination of major, minor and trace elements, increasing the counting } \\
\text { rate gain of fluorescent intensity for a better detection. }\end{array}$ \\
WDXRF & $\begin{array}{l}\text { Mapping of Bromine intensities and by use of the iterative method of Fundamental Parameters (FP) } \\
\text { can be obtained elemental concentrations (corresponding at depths of some hundredths of } \mu \mathrm{m}) .\end{array}$ \\
Qualitative determination of Bromine at surface level (at depth of tens of nm). See Section S7 at the \\
SR-GIXRF & $\begin{array}{l}\text { Supplemental Material. } \\
\text { Semi-quantitative determination of Bromine (see Section S9 at the Supplemental Material). } \\
\text { LIBS }\end{array}$ & $\begin{array}{l}\text { The quantitative determination of Bromine at bulk level. } \\
\text { Characterization of the Bromine functional groups contained in the chemical structure of these hybrid } \\
\text { Volumetric Determination }\end{array}$ \\
mV-Vis/IR/MS/EXAFS/DRX &
\end{tabular}

\section{Results and Discussion}

\subsection{X-ray Fluorescence Spectrometry: Energy Dispersive $X$-ray Fluorescence Spectrometry (EDXRF)/Wavelength Dispersive X-ray Fluorescence Spectrometry (WDXRF)}

Figures $1 \mathrm{a}$ and $1 \mathrm{~b}$ depict the ratios of the intensities of Bromine, Tungsten and Silicon for the PDMSUr-PWA samples (as function of their corresponding nominal PWA concentrations) determined by EDXRF and WDXRF analysis respectively.

For Bromine ratios in EDXRF results (Figure 1a) can be seen that at $25 \%, 35 \%$ and $40 \%$ PWA there are changes in their profile (inflexion points). This observation is supported by WDXRF results (Figure 1b), which shown that in the range
[33-38\% PWA] there is an inflexion point at the Bromine ratios profile. From $50 \%$ PWA (Figure 1a), the profiles of intensities of Bromine, Tungsten and Silicon undergo a significant decrease, which are indicatives of segregation at thickness (see also Section S1 at the Supplemental Material).

\subsection{Synchrotron Radiation Micro X-ray Fluorescence $(S R-\mu X R F)$}

\subsubsection{Bromine, Tungsten and Silicon Intensities Ratios}

Figure 2 depicts the ratios of the Bromine, Tungsten and Silicon intensities, determined by SR- $\mu$ XRF, as function of its corresponding nominal PWA concentration for the PDMSUr-PWA samples:

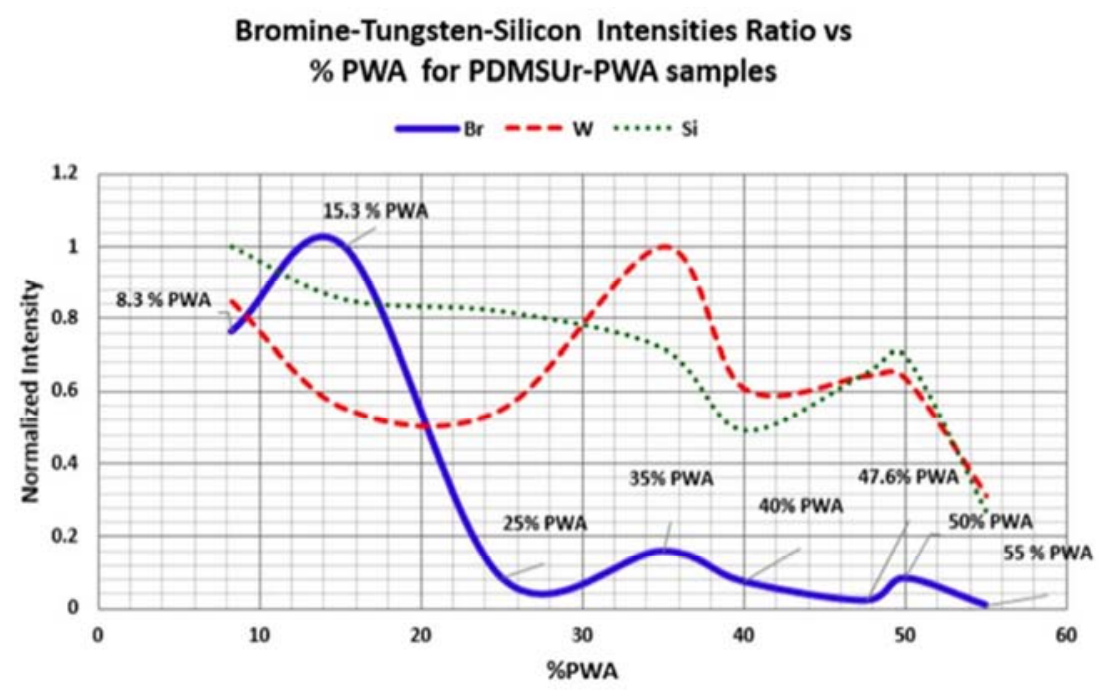

Figure 2. SR- $\mu X R F$ intensities ratios as function of \% PWA for PDMSUr-PWA samples. Bromine (solid blue line), Silicon (dotted green line) and Tungsten (dashed red line).

Figure 2 reveals that the highest and lowest Bromine concentration ratios correspond to the PDMSUr (15.3\% PWA) and PDMSUr (55\% PWA) samples respectively. However, among the lowest concentrations of Bromine (at 25-50\% PWA range) there is a change in its profile coinciding with the inflexion points obtained from EDXRF and WDXRF analyses. Results obtained by EDXRF (Figure 1a) and SR- $\mu$ XRF (Figure 2) exhibit similar profiles for Bromine concentration (the same tendency is observed for Silicon). We can see that between $8.3 \%-15.3 \%$ PWA there is a maximum for Bromine intensities at micrometric level. At higher values of this range, there are indicatives of segregation of $\mathrm{Br}$ at the thickness of PDMSUr-PWA films.

\subsubsection{SR- $\mu X R F$ Maps of Bromine Intensities}

Figure 3 shows the SR- $\mu$ XRF maps of Bromine (XRF line $\mathrm{Br}-\mathrm{K}_{\alpha}$ ) intensities as function of the PWA content in the preparation of the PDMSUr-PWA samples.

Figure 3 reveals two main ranges: 1) From 1.0 to $15.3 \mathrm{wt} \%$ PWA, the intensities ranging from 80 (lowest value at $1.0 \mathrm{wt} \%$ PWA) to 1200 counts (highest value at $15.3 \mathrm{wt} \%$ PWA); 2) 
From 25 to $55 \mathrm{wt} \%$ PWA, the intensities ranging from 0 (lowest value) to 135 counts (highest value). These gradients at surface are in agree with their corresponding gradients through the thickness (see also Section S3 at the Supplemental
Material). However, at $40 \%$ PWA the intensities present the lowest values. Referent to the distribution of Bromine intensities among the samples analyzed, were not exhibited a uniform pattern with the increase of PWA content. (a) $1.0 \mathrm{wt} \%$ PWA

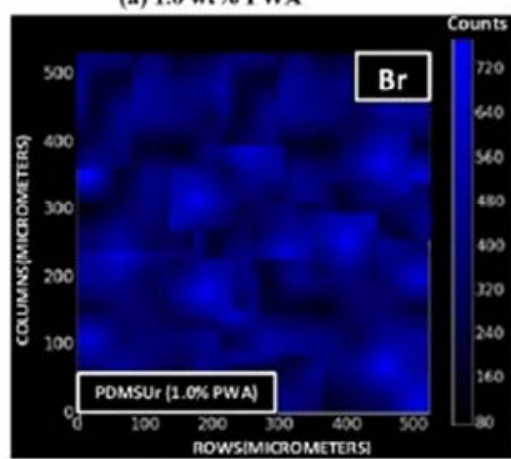

(d) $25.0 \mathrm{wt} \%$ PWA

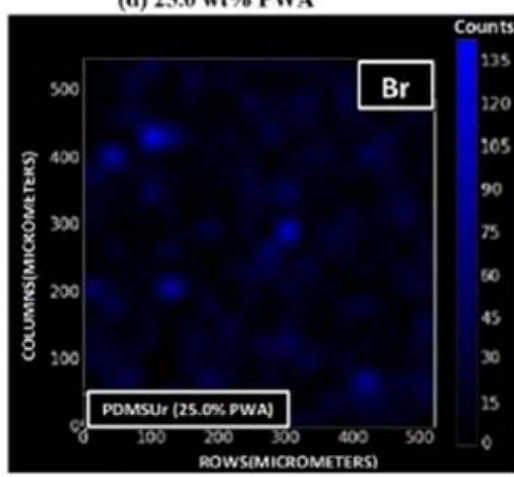

(g) 47.6 wt $\%$ PWA

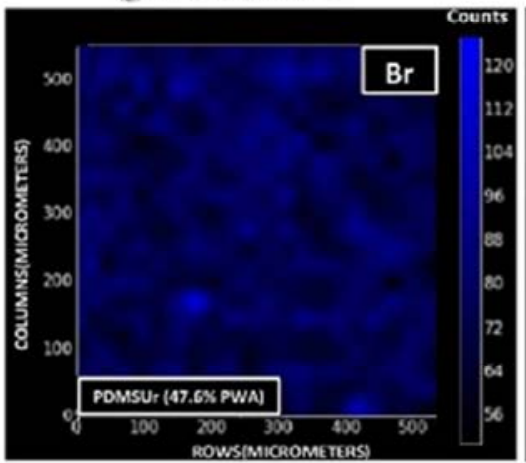

(b) 8.3 wt $\%$ PWA

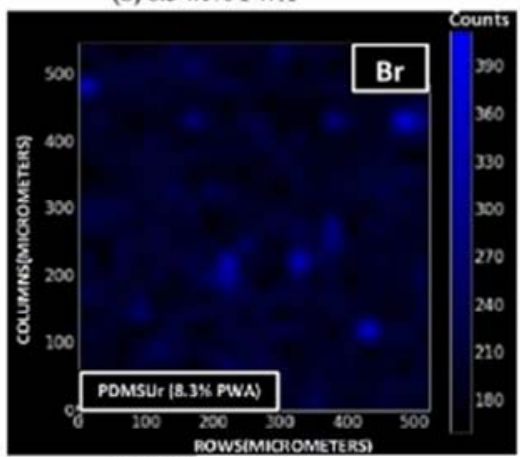

(e) $35.0 \mathrm{wt} \%$ PWA

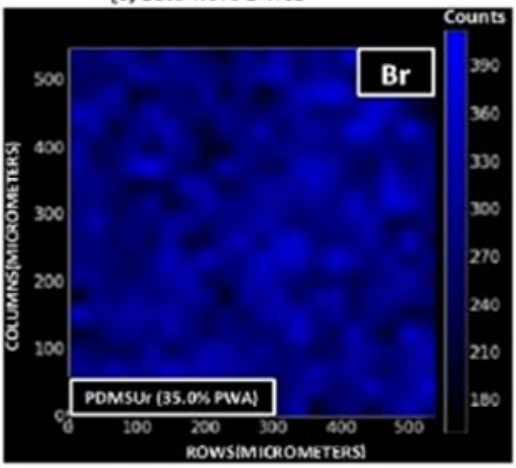

(h) $50.0 \mathrm{wt} \% \mathrm{PW} / \mathrm{A}$

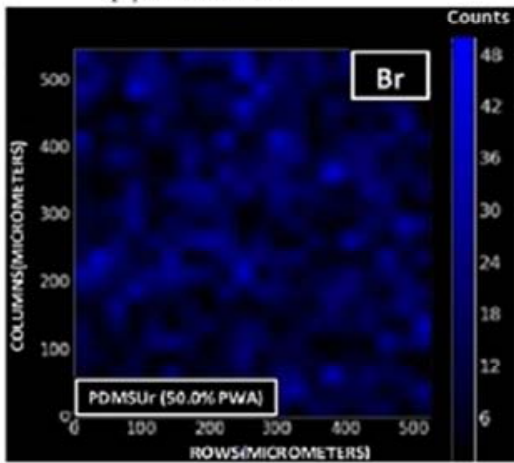

(c) $15.3 \mathrm{wt} \%$ PWA

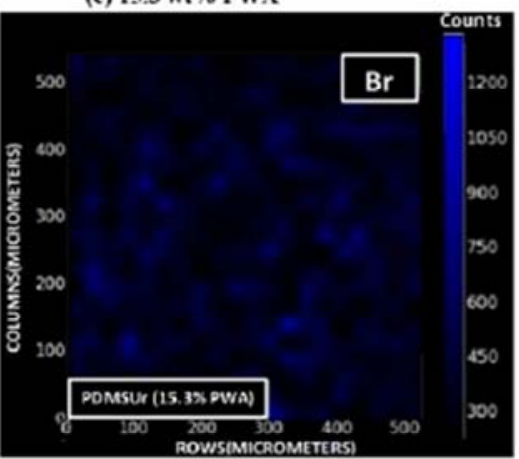

(1) 40.0 wt\% PWA

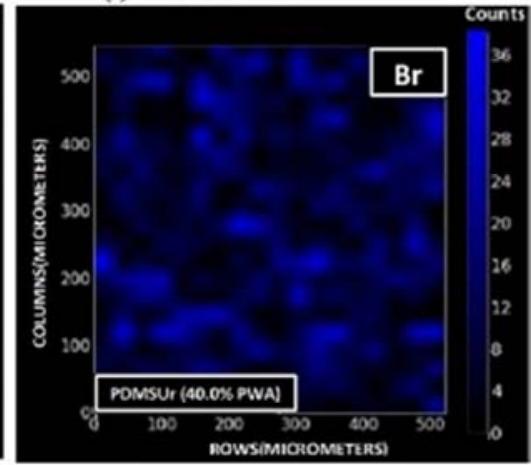

i) $55.0 \times 1 \% \mathrm{PWA}$

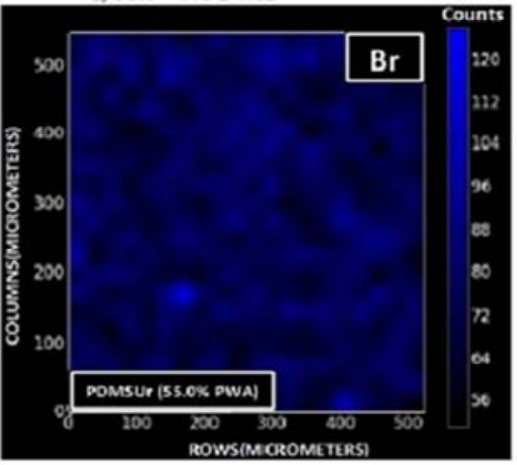

Figure 3. SR- $\mu X R F$ maps of Bromine intensities for the PDMSUr-PWA samples with different PWA content.

PDMSUr-PWA films containing 1\%, 35, 40 and 55\% PWA have shown the greatest degree of homogeneity in the Bromine distribution. This homogeneity for the film containing 35\% PWA at micrometric level is complemented by the LIBS results that reflect homogeneity of Bromine at millimetric level (see also Section S9 at the Supplemental Material). The samples containing $1 \%$ and $35 \%$ PWA have exhibited the higher concentrations of Bromine at top surface, presenting brittle and adhesive characteristics respectively under the adhesion test $[9,10,12]$. From this observation, we can correlate the presence of Bromine with the adhesive properties of the PDMSUr-PWA films, which were evaluated by the pull-off-strength test. During these tests were found that the pull-off-strength of such coatings raised more than $100 \%$ for steel SS316L and Ti6Al4V substrates, after Laser and
Plasma oxidation treatments, compared with these substrates without physical treatments $[9,12]$. These results obtained for PDMSUr-PWA films may be based on the high contents of APTES and PWA in their surface chemical compositions. However, due to the lower free surface energy of PDMS, the presence of APTES at top surface would be possible mainly through of PWA [9, 10]. For the PDMSUr (35\% PWA) sample that exhibited high value of adhesion strength, also possess the highest Tungsten concentrations at surface as was reported by Elguera et al [26]. The increase of PWA content favoring the increase in the stiffness of PDMSUr-PWA films, due to that accelerate the formation of silicates three-dimensional network, consequently the elastic modulus and hardness $[12,26]$. In addition, the amino-silane (APTES) incorporated in Polyurethanes (PU) chains can reduce the 
inter-association among their soft segments and limits the capacity of them in order to crystallize, thus generate the conditions for keep or increase adhesion properties, as was reported by Zhao-Sheng et al [42]. For PDMSUr (1\% PWA) sample the PWA concentrations at surface are low, thus, one explanation of its high value of adhesion strength can be due to the high Bromine concentrations. These high contents, which increasing the surface roughness after high temperatures treatments, could increase the sticking capacity. In previous studies, the presence of Bromine radicals generated by UV radiation produces increase of the surface roughness of PDMS, presenting wells with areas of tenths of $\mu \mathrm{m}^{2}$ and depths of few $\mathrm{nm}$, according to Cabrera et al [5].

\subsubsection{SR- $\mu$ XRF Maps of the Spatial Correlation Between Bromine and Tungsten}

Figure 4 shows the SR- $\mu$ XRF maps of the spatial correlation between Bromine (XRF line $\mathrm{Br}-\mathrm{K}_{\alpha}$ ) and Tungsten (XRF line $\mathrm{W}-\mathrm{L}_{\alpha}$ ) intensities for the PDMSUr-PWA samples:

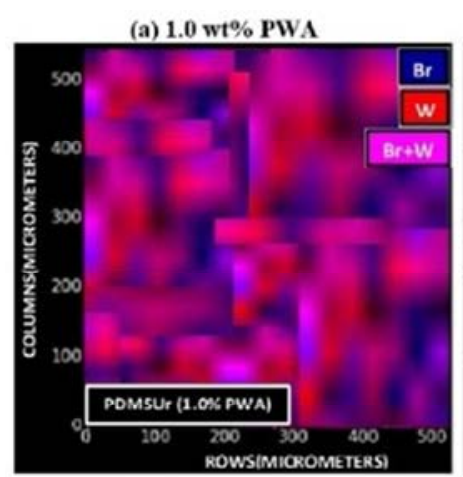

(d) 25.0 wt $\%$ PWA

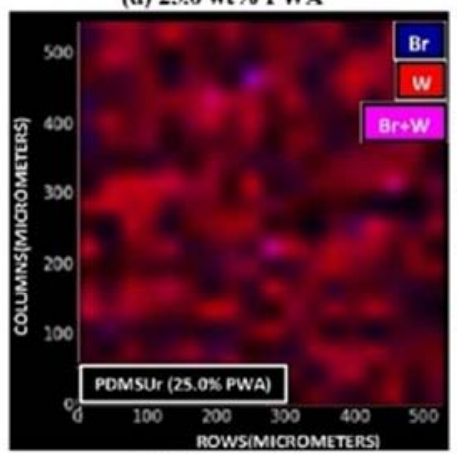

(g) $47.6 \mathrm{wt} \%$ PWA

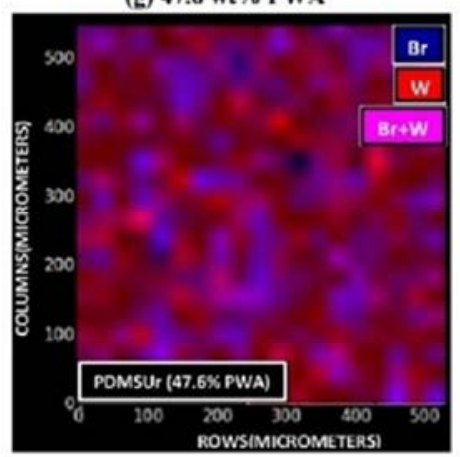

(b) $8.3 \mathrm{wt} \%$ PWA

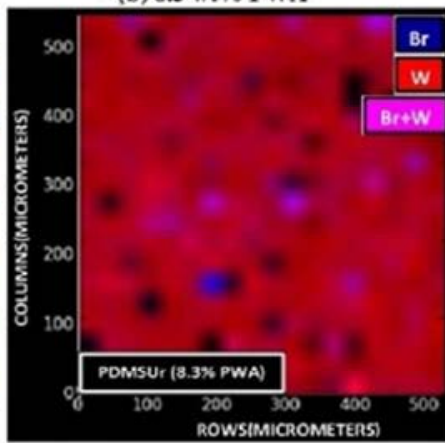

(e) $35.0 \mathrm{wt} \%$ PWA

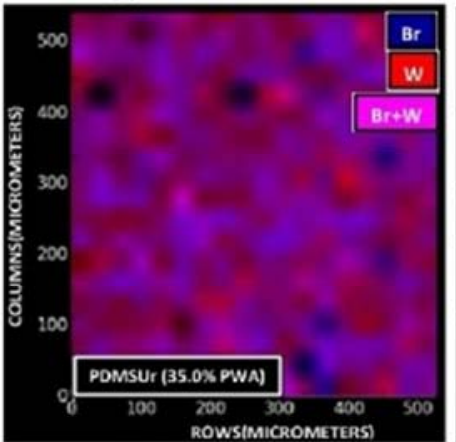

(h) $50.0 \mathrm{wt} \%$ PWA

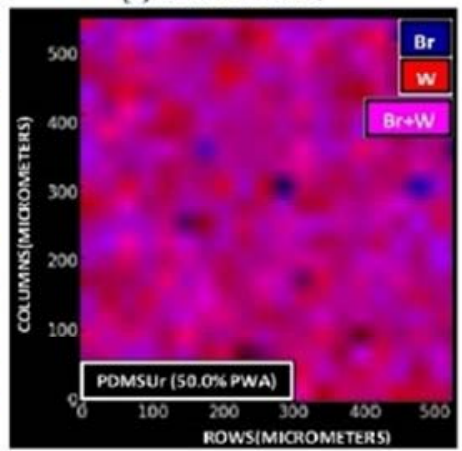

(c) $15.3 \mathrm{wt} \%$ PWA

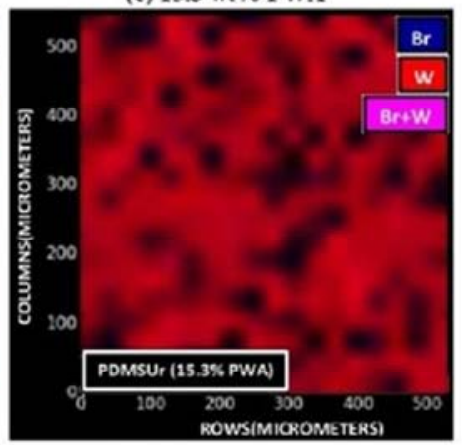

(f) 40.0 wt $\%$ PWA

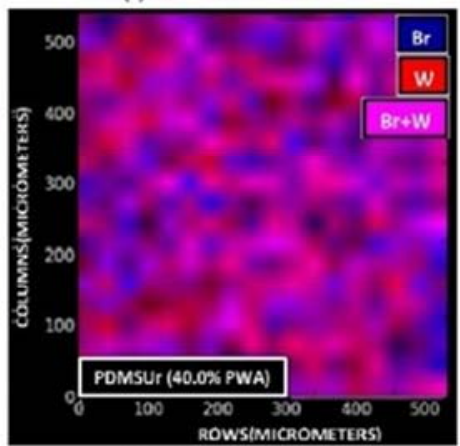

(i) $55.0 \mathrm{wt} \%$ PWA

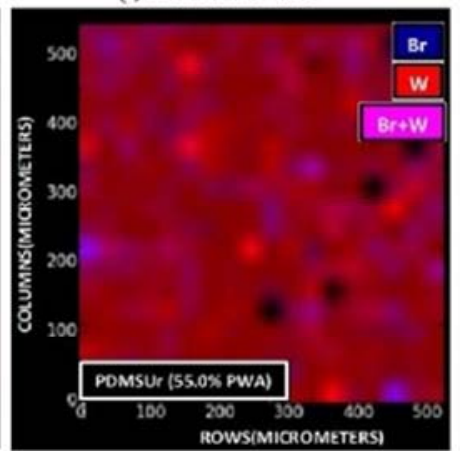

Figure 4. SR- $\mu X R F$ maps of correlation of Intensities between Bromine (blue regions), Tungsten (red regions) and Bromine + Tungsten (magenta regions) of the PDMSUr-PWA samples as function of PWA content.

Figure 4 reveals a heterogeneous distribution pattern of Bromine + Tungsten (magenta regions) at the PDMSUr-PWA samples. Up to $15.3 \%$ PWA there is increase of Bromine regions (blue). At this concentration, is observed high values for Bromine (Figures 2 and $3 \mathrm{c}$ ) and low ones for Tungsten [40]. From $25 \%$ to $50 \%$ PWA, it is observed an increase in the common regions Bromine + Tungsten. In this concentrations range, at 35\% PWA and $50 \%$ PWA the Bromine exhibit slightly increases in their intensities, which is manifested in their corresponding SR- $\mathrm{XRF}$ maps shown in Figures $4 \mathrm{e}$ and $4 \mathrm{~h}$ respectively. For 55\% PWA, there is an important reduction of Bromine presence, indicating the segregation of this element at thickness of these materials, as has been reported for Tungsten also [26], reason by which its corresponding map (Figure 4i) show common regions of these elements mainly and almost not isolated regions of $\mathrm{Br}$ and $\mathrm{W}$. Aiming for potential applications, in PDMSUr-PWA films, the interactions between organic amines and polyoxometalates $\left(\mathrm{NH}_{3}{ }^{+--}\left[\mathrm{PW}_{12} \mathrm{O}_{40}\right]^{3-}\right)$ present synergistic effects by combining 
cathodic protection and an oxidation inhibitor characteristic respectively [9]. As was reported by Elguera et al, at the surface of these films, up to $15 \%$ PWA content approximately, there would be predominance of electrostatic interactions among PWA and amines groups [26]. From anti-corrosive test of Stainless Steel 307 (SS307) coated with PDMSUr-PWA film containing $35 \%$ PWA could be inferred that this film behaves as a diffusional barrier at the interface between metal and essential components to corrosion, such as $\mathrm{H}^{+}$ions, water and oxygen [9, 11, 12]. According to the literature, tungstate anions (e.g. $\left[\mathrm{PW}_{12} \mathrm{O}_{40}\right]^{3-}$ ) constitute corrosion inhibitors, because they can diffuse to the liquid/film interface, passivating the surface and consequently prevent the corrosion of metal [43]. From 35\% PWA to 50\% PWA of content at the surface of these films there would have predominance the forces based on the strong interaction between PWA and ormosil [26]. For values greater than 50\% PWA, there is presence of non-polar forces mainly at the surface of PDMSUr-PWA films due there is a significant Bromine and Tungsten segregation at thickness. Besides of this, if we considerate that $\mathrm{Br}^{-}$impart passivity to the alloys, these materials are candidate as coatings against corrosion of metals, especially the films containing 1\%, 35, 40, 47.6, and 50\% PWA [44, 45].

\subsubsection{SR- $\mu$ XRF Maps of the Spatial Correlation Between Bromine and Silicon}

Figure 5 shows the SR- $\mu$ XRF maps of the spatial correlation between Bromine (XRF line $\mathrm{Br}-\mathrm{K}_{\alpha}$ ) and Silicon (XRF line $\mathrm{Si}-\mathrm{K}_{\alpha}$ ) Intensities for the PDMSUr-PWA samples:

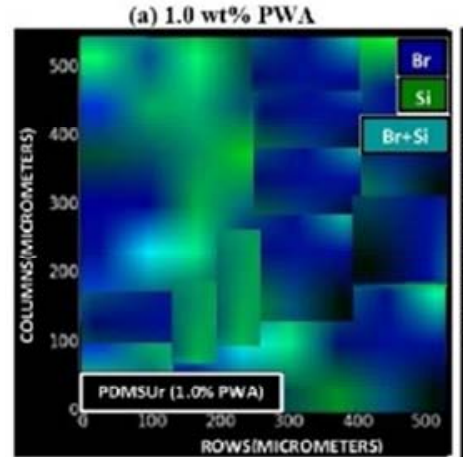

(d) $25.0 \mathrm{wt} \%$ PWA

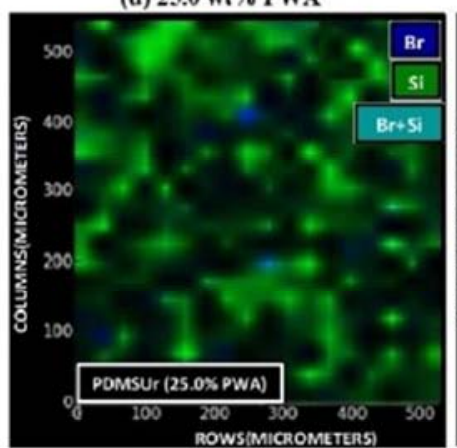

(g) $47.6 \mathrm{wt} \%$ PWA

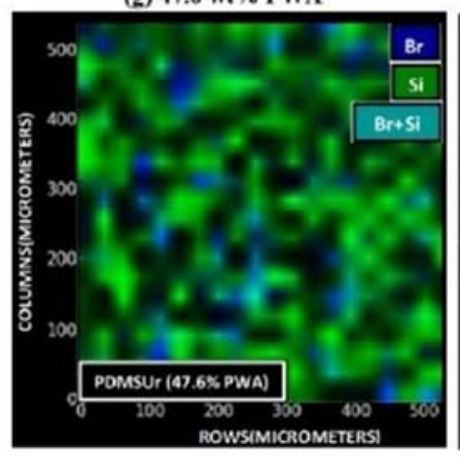

(b) 8.3 wt $\%$ PWA

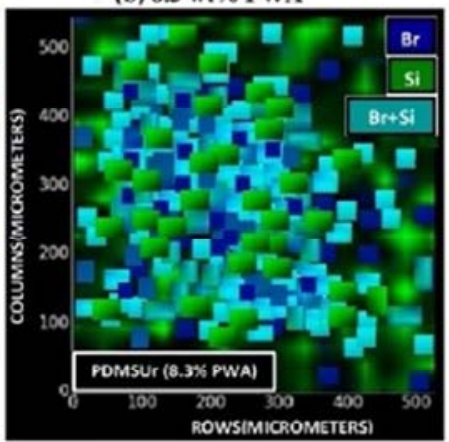

(e) $35.0 \mathrm{wt} \%$ PWA

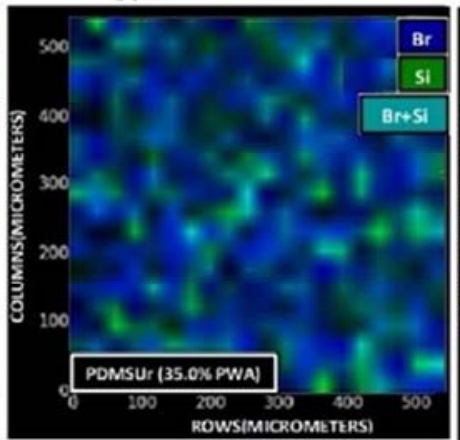

(h) $50.0 \mathrm{wt} \%$ PWA

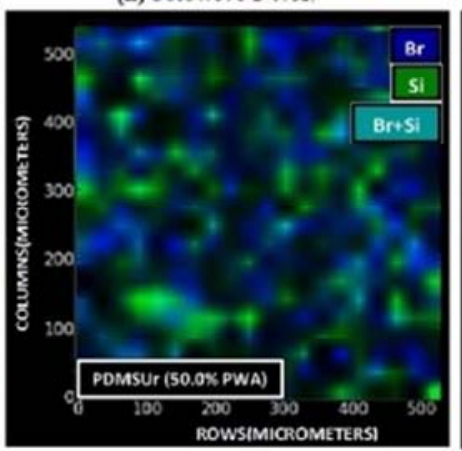

(c) $15.3 \mathrm{wt} \%$ PWA

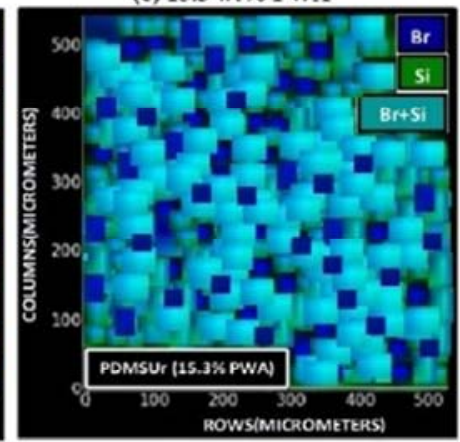

(f) $40.0 \mathrm{wt} \%$ PWA

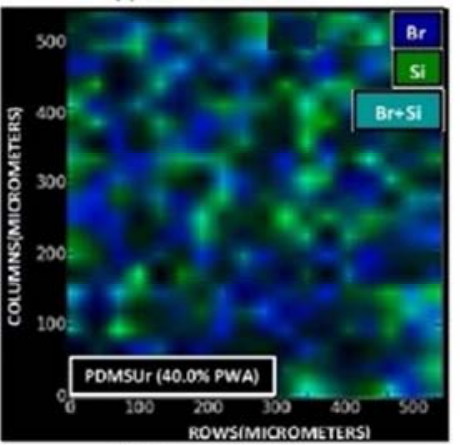

(i) $55.0 \mathrm{wt} \%$ PWA

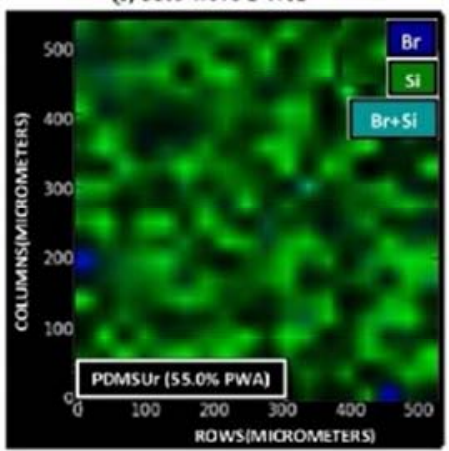

Figure 5. SR- $\mu X R F$ maps of correlation of Intensities between Bromine (blue regions), Silicon (green regions) and Bromine + Silicon (cyan regions) of the PDMSUr-PWA samples as function of PWA content.

Figure 5 reveals that at 1\%-15\% PWA (Figures 5a-5c) and $35 \%-50 \%$ PWA (Figures $5 \mathrm{e}-5 \mathrm{~h}$ ) ranges of the PDMSUr-PWA samples, there is possibility of interaction of Bromine + Silicon (cyan regions). At 25\% PWA (Figure 5d) and 55\% PWA(Figure 5i) there is mainly isolated Silicon regions and minimum presence of Bromine. These observations are supported on the hypothesis of segregation of this element at thickness (see Figures 2 and also Section S5 at the at the Supplemental Material). Taking in consideration that Polydimethylsiloxane co-polymers exhibit excellent thermal properties, the 
PDMSUr-PWA films containing 25\% and 55\% PWA would be the most suitable for thermal insulators, because the Bromine is present at thickness mainly, avoiding the possible emission of $\mathrm{HBr}_{(\mathrm{g})}$ at high temperatures (Hydrobromic acid Boiling point: $124.3^{\circ} \mathrm{C}$ at $\left.101323 \mathrm{~Pa} / 760 \mathrm{~mm} \mathrm{Hg}\right)$. The Thermo-gravimetric analysis (TGA) of PDMSUr films reported in the study of Kelen Aguiar et al shown major weights losses between $180^{\circ} \mathrm{C}$ and $600^{\circ} \mathrm{C}$ mainly [11]. At around $190^{\circ} \mathrm{C}$ occurred the desorption of structural water of PWA, and water formed by the condensation. PDMSUr system can improve their thermal properties with the addition of APTES, because postpone its thermal degradation [11]. The Keggin structure of PWA is decomposed approximately at $612^{\circ} \mathrm{C}$ [46]. TGA of APTES show decomposition at ranges $135-225^{\circ} \mathrm{C}, 225-320^{\circ} \mathrm{C}$ and $320-450^{\circ} \mathrm{C}$ corresponding to the end capped, rigid and soft segments, respectively [13]. $\mathrm{H}_{3} \mathrm{PW}_{12} \mathrm{O}_{40} \cdot 6 \mathrm{H}_{2} \mathrm{O}$ (the most stable hydrate at normal conditions) losses up to 6 molecules of water between $170^{\circ} \mathrm{C}$ and $240^{\circ} \mathrm{C}$ and became anhydrous phase $\left(\mathrm{H}_{3} \mathrm{PW}_{12} \mathrm{O}_{40}\right)$, which was stable up to $400^{\circ} \mathrm{C}$. Thus, the suitable PDMSUr-PWA films chosen as thermal insulators mentioned above would be use up to range $180-225^{\circ} \mathrm{C}$ approximately. Considering the non-polar characteristics of PDMS (excellent water repellence) and $\mathrm{Br}$ (hydrophobicity), the PDMSUr-PWA samples containing $1.0 \%, 15,35,40$, and $50 \%$ PWA would be suitable as inert materials under the presence of aqueous solutions of polar chemical reagents. Hydrophilicity of the materials is determined by their contact angle and surface energy $[9,12]$. The synthesized PDMSUr presented hydrophobic surfaces with high contact angles $102-104^{\circ} \mathrm{C}$ (independent of PWA content) close to the polydimethylsiloxane (PDMS) contact angle $\left(105.5^{\circ} \mathrm{C}\right)$ and with surface free energy values of PDMSUr $\left(16.1 \pm 1.1 \mathrm{mNm}^{-1}\right)$, which varies slightly of the correspond value of PDMS $\left(11.5 \mathrm{mNm}^{-1}\right)[9,12,42]$.

Thus, these results constitute indicatives about that the surface of PDMSUr-PWA films would be dominate by nonpolar groups of PDMSUr and those attached to this (e.g. $\left.-\mathrm{CH}_{3},-\mathrm{OCH}_{3},-\mathrm{COOCH}_{3},-\mathrm{Br}\right)$, meanwhile the polar groups, include the heteropoly acids (PWA) at lower PWA contents, are arranged in positions inside of this material [9]. The SR- $\mu$ XRF maps (Figure 5) of the spatial correlation between Bromine (XRF line $\mathrm{Br}-\mathrm{K}_{\alpha}$ ) and Silicon (XRF line $\mathrm{Si}-\mathrm{K}_{\alpha}$ ) can be reinforced in arguments by the corresponding $\mathrm{SR}-\mu \mathrm{XRF}$ maps of the spatial correlation of intensities between Bromine (XRF line $\mathrm{Br}-\mathrm{K}_{\beta}$ ) and Silicon (XRF line $\mathrm{Si}-\mathrm{K}_{\beta}$ ) shown in Section S5 at the Supplemental Material. The XRF $\mathrm{K}_{\beta}$ lines involve electrons more external than the corresponding to the $K_{\alpha}$ lines, being that for the case of Silicon are involved their valence electrons. Thus, indirectly there is possibility to have a notion about the chemical interactions between PDMS-Br and/or APTES-Br. From those SR- $\mu$ XRF maps, we can observe a significant degree of the spatial superposition between $\mathrm{Si}-\mathrm{K}_{\beta}$ and $\mathrm{Br}-\mathrm{K}_{\beta}$ lines, aiming to the probable chemical interactions between the Silicon and Bromine, which is supported by indicatives from IR analysis mentioned in the sequence. FTIR spectra of PDMSUr synthesized have shown peaks between 1530-1540 $\mathrm{cm}^{-1}$ [9-11]. The peak at $1533 \mathrm{~cm}^{-1}$, which can be assigned to the bromine end-capped PDMS-Br, and the peak at $1537 \mathrm{~cm}^{-1}$ was related to the urethane linkage (stretching of the urethane bond $\mathrm{N}-\mathrm{H})$ [9-12]. Around $1650 \mathrm{~cm}^{-1}$, there is another characteristic peak could correspond to PDMS-Br [47]. In addition, between $1740-1750 \mathrm{~cm}^{-1}$ there are the peaks at 1743 $\mathrm{cm}^{-1}$ and $1745 \mathrm{~cm}^{-1}$, corresponding possibly to the ester group (signal of synthesized PDMS-Br), and the free urethane peak [47]. Thus, SR- $\mu$ XRF maps and FTIR analysis can constitute indicatives of the interaction PDMS-Br. For APTES, the FTIR spectrum shows peaks at range $2887-2970 \mathrm{~cm}^{-1}$ corresponding to $-\mathrm{CH}_{2}$ stretching vibration; while the FTIR spectra of PDMSUr shown peaks at the range $3050-2750 \mathrm{~cm}^{-1}$ [9-12, 42, 47-49]. Thus, there are not suffice indicatives of the existence of the interaction APTES-Br; maybe due to the peaks overlapping of PDMSUr, APTES, PWA, and groups contained $\mathrm{Br}$. Additionally, it is not established yet if the Bromine is as atomic, molecular and/or ionic form. For this reason, are necessary additional characterization techniques or methods of analyses (e.g. Mass Spectrometry, Voltammetry/Potentiometric Titration, UV-Vis), in order to evidencing the presence of Bromine species (see Section S8 at the Supplemental Material).

\subsection{Hypotheses of Interactions of Bromine and Their Possible Species Present}

1) If there is a spatial correlation between $X R F$ internal lines $\mathrm{Br}-\mathrm{K}_{\alpha} / \mathrm{W}-\mathrm{L}_{\alpha}$ (Figure 4), and also between XRF internal lines $\mathrm{Br}-\mathrm{K}_{\beta} / \mathrm{W}-\mathrm{M}_{\alpha}$ (see Section $\mathrm{S} 4$ at the Supplemental Material) then could exist intermolecular/interatomic interactions mainly, existing compounds like $\left(\mathrm{Br}^{ \pm 1}\right)_{\mathrm{y}}\left(\left[\mathrm{PW}_{12} \mathrm{O}_{40}\right]^{3-}\right)_{\mathrm{z}}$. If there is a spatial correlation between $\mathrm{Br}-\mathrm{K}_{\alpha} / \mathrm{W}-\mathrm{L}_{\alpha}$ lines and not between $B r-K_{\beta} / \mathrm{W}-\mathrm{M}_{\alpha}$ lines then do not exist intermolecular/interatomic interactions, could exist intramolecular interactions mainly inside the Keggin structure of $\left[\mathrm{PW}_{12} \mathrm{O}_{40}\right]^{3-}$ ).

2) If there is a spatial correlation between $\mathrm{Br}-\mathrm{K}_{\alpha}$ and $\mathrm{Si}-\mathrm{K}_{\alpha}$ lines and between $\mathrm{Br}-\mathrm{K}_{\beta}$ and $\mathrm{Si}-\mathrm{K}_{\beta}$ lines then can be inferred the existence of intermolecular/interatomic interactions between Silicon ions (e.g. $\mathrm{Si}(\mathrm{OH})_{2}{ }^{2+}$ ) and the Bromine species (atomic, molecular or ions) maybe via chemical bonding (e.g. through of PDMS-Br directly or by the Keggin structure indirectly), and/or physical forces. If there is a spatial correlation between $\mathrm{Si}-\mathrm{K}_{\alpha}$ and $\mathrm{Br}-\mathrm{K}_{\alpha}$ lines and not between $\mathrm{Si}-\mathrm{K}_{\beta}$ and $\mathrm{Br}-\mathrm{K}_{\beta}$ then can be inferred that there is no existence of intermolecular/interatomic interactions between Silicon and Bromine rather could constitute indicatives of intramolecular interactions of Bromine and Silicon species in direct form as PDMS-Br or through the Keggin structure according to proposed by Kozhevnikov et al [50].

3) If there would be only Bromine from PDMS-Br (at the top surface of PDMSUr-PWA films) the tendency of [Br] with the increase of [PWA] would have to be a descendent line. However, SR- $\mu$ XRF analysis (Figure 2) have presented some inflexion points in Bromine concentration tendency. From this observation, one can 
deduce that there is Bromine in another form different of PDMS-Br, maybe as atomic, molecular or free-ionic forms those are able to diffuse through the thickness of PDMSUr-PWA films. Depending of the size of the Bromine specie could be interacting also inside of Keggin structure of phosphotungstates (PWA) according to the proposed by Kozhevnikov et al [50].

From these hypotheses of Bromine, Silicon and Tungsten $\mathrm{XRF}$ lines could be exist ionic compounds e.g. $\left(\mathrm{Si}(\mathrm{OH})_{2}{ }^{2+}\right) \mathrm{x}\left(\mathrm{Br}^{ \pm 1}\right)_{\mathrm{y}}\left(\left[\mathrm{PW}_{12} \mathrm{O}_{40}\right]^{3-}\right)_{\mathrm{z}}$ or molecular compounds e.g. $\left(\mathrm{Si}(\mathrm{OH})_{2}{ }^{2+}\right) \mathrm{x}====\left(\mathrm{Br}^{ \pm 1}\right)_{\mathrm{y}}====\left(\left[\mathrm{PW}_{12} \mathrm{O}_{40}\right]^{3-}\right)_{\mathrm{z}}$ or present in these hybrid nanomaterials.

\subsection{Analysis of Segregation of Bromine at the PDMSUr-PWA Films}

Table 2 show the concentrations of Bromine (obtained from SR- $\mu$ XRF, EDXRF, and Volumetric analyses) as function of \% PWA for the PDMSUr-PWA films (see Section $\mathrm{S} 8$ at the Supplemental Material).

Table 2. Bromine Concentrations obtained for PDMSUr-PWA films.

\begin{tabular}{|c|c|c|c|c|}
\hline PDMSUr-PWA & {$[P W A]^{a}(w t / w t \%)$} & {$[\mathrm{Br}](w \mathrm{t} / \mathrm{wt} \%)$ SR- $\mu$ XRF PyMCA } & [Br] (wt/wt\%) EDXRF & {$[\mathrm{Br}](\mathrm{wt} / \mathrm{wt} \%)$ Volumetric analysis ${ }^{\mathrm{b}}$} \\
\hline PDMSUr (8.3\% PWA) & 8.3 & $2.02 \pm 0.84$ & $2.45 \pm 0.43$ & $\mathrm{NQ}^{\mathrm{c}}$ \\
\hline PDMSUr (15.3\% PWA) & 15.3 & $2.34 \pm 0.91$ & $2.37 \pm 0.28$ & NQ \\
\hline PDMSUr (25\% PWA) & 25 & $0.19 \pm 0.08$ & $1.32 \pm 0.18$ & $1.91 \pm 0.04$ \\
\hline PDMSUr (35\% PWA) & 35 & $0.23 \pm 0.12$ & $1.58 \pm 0.08$ & $1.74 \pm 0.04$ \\
\hline PDMSUr (40\% PWA) & 40 & $0.10 \pm 0.05$ & $1.56 \pm 0.09$ & NQ \\
\hline PDMSUr (47.6\% PWA) & 47.6 & $0.04 \pm 0.02$ & $1.51 \pm 0.18$ & NQ \\
\hline PDMSUr (55\% PWA) & 55 & $0.02 \pm 0.02$ & $1.37 \pm 0.06$ & NQ \\
\hline
\end{tabular}

${ }^{\text {a }}$ Relative to the total mass of PDMSUr precursors (CCPDMS + APTES) without solvent [10].

${ }^{\mathrm{b}}$ Reference [40], p. 378.

${ }^{\mathrm{c}} \mathrm{NQ}$ : not was quantified

Table 2 shows from XRF results that at 25\% PWA there is a significant diminution in surface Bromine concentration, which is agree with their corresponding intensities profiles presented in the Figures 1 and 2 by XRF and SR- $\mathrm{XXRF}$ respectively, which constitute indicatives of the segregation of Bromine at thickness of these materials.

\subsection{Correlation Between Structure and Properties of PDMSUr-PWA Films}

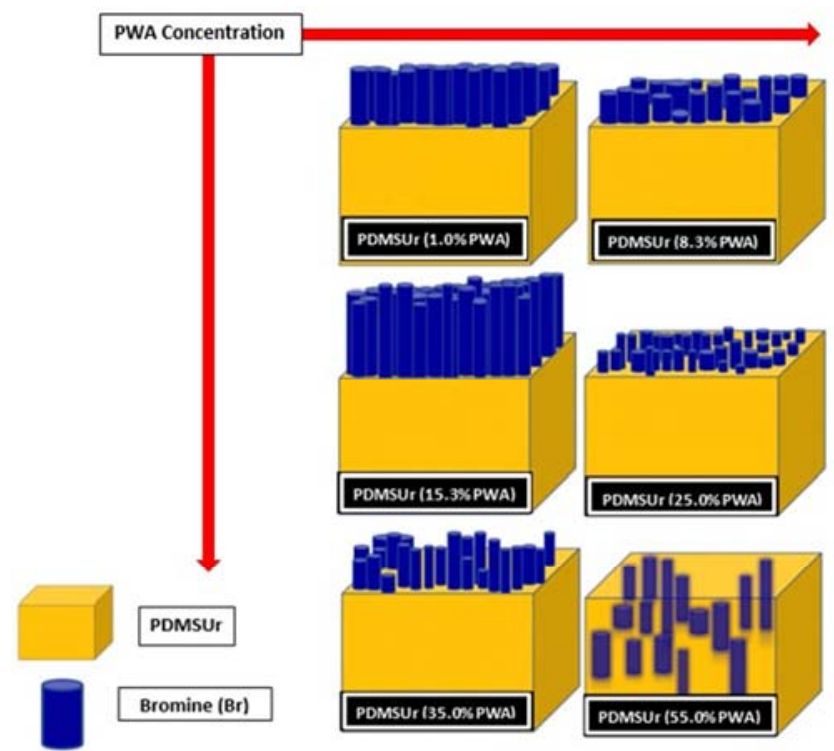

Figure 6. Models of Bromine distribution for PDMSUr-PWA films as function of PWA content.

Based on all these results were developed models of Tungsten distribution in function of \%PWA, which are showing in Figure 6.

From Figure 6 we can observe that there is no a regular distribution pattern of Bromine as function of PWA content. In the sequence, is presenting the details of Bromine gradients at vertical and horizontal directions.

Vertical gradient: From comparison of XRF and Volumetric results for the PDMSUr-PWA films, it can be inferred that on average insofar the PWA content increases the Bromine concentration obtained by XRF diminish. Thus, the segregation of Bromine at thickness is predominant for PWA concentrations $>15.3 \% \mathrm{wt} / \mathrm{wt}$. It is unknown yet if the Bromine is present as atomic and/or molecular forms in the three-dimensional network of the silicates and the reticular structure of phosphotungstates, which are connected more possibly through Coulombic interactions [9]. Might be necessary Extended X-ray Absorption Fine Structure (EXAFS) studies for Bromine, in order to clarify this aspect.

Lateral gradient: Due to the non-polarity of PDMS and the $\mathrm{Br}$, the more probable is that at PWA concentrations $<15.3 \%$ $\mathrm{wt} / \mathrm{wt}$, the predominant forces be non-Coulombic interactions and/or intermolecular forces at surface of these hybrid materials. From SR-TXRF/SR-GIXRF results (see Section S7 at the Supplemental Material), at the first nanometers of depth, SR-TXRF results have shown that up PWA concentrations $<40 \% \mathrm{wt} / \mathrm{wt}$ the forces above mentioned would predominate. Thus, it can be inferred the presence of Bromine at the top surface (few tenths of nanometers of depth) [40]. SR- $\mu$ XRF maps (see Figure 3 and also Section S3 at the Supplemental Material) have shown heterogeneity of Bromine distributions at micrometric level. 


\subsection{Potential Application of PDMSUr-PWA Films for Fuel Cells}

\subsubsection{PDMSUr-PWA Films as Proton Exchange Membrane Fuel Cells (PEMFCs)}

In the structure of PDMSUr-PWA films could be present the inter-molecular (hydrophilic-hydrophilic interactions between PWA clusters and the PDMS matrix) and intra-molecular proton transfer pathways, such as was reported by Zhou et al [15] for membranes based on Silica and PWA (proton carrier) for use as for Proton exchange membrane fuel cells (PEMFCs). These membranes exhibit high-power density, low-greenhouse gas emission and high efficiency [14-15]. PDMSUr-PWA films possess such properties as structural stability and characteristics for medium-high proton conductivity, necessaries in order to attain an optimum performance.

These films could be performed as PEMFCs operating up temperatures $180-225^{\circ} \mathrm{C}$, as mentioned above in the section 4.2.4, corresponding to the respective loss of water (see TGA), because at temperatures more than this limit the conductivity of membranes start to diminish, affecting the fuel cells performance. Protons transport, which depends of relationship between the packing structure of PWAs and/or nanochannels in the polymer domains [1], could be performed through of channels within PDMSUr-PWA films, according to the model of Tungsten (from PWA) distribution reported by Elguera et al [26]. For these films the pathways of proton transfer can be intramolecular (within isolated PWA molecules) and intermolecular (among PWA molecules and their surrounding) along the hydrogen bonds. For intramolecular proton transfer pathway, with low quantities of water can increase the protons velocities. At very low PWA contents, the proton conductivities for this system are too low $[14,15]$. The intermolecular pathway would have predominance at high PWA contents (67-83 wt\%), in which the distances between the neighbouring PWA molecules are less than $17.0 \AA$. Among the useful properties of Keggin-type heteropolyacids for applications in fuel cells are mentioned the high polarizability, surface charge distribution, redox potentials for electrons and protons transfer. The intramolecular protons transfer can be supported by the study of Kozhevnikov et al [50]. The crystal PWA Keggin structure depends on the amount of water of crystallization contained, result from its molecular composition, besides of their anions (heteropolyanions) and cations $\left(\mathrm{H}^{+}, \mathrm{H}_{3} \mathrm{O}^{+}, \mathrm{H}_{5} \mathrm{O}_{2}^{+}\right.$, and others that act as counter-cations). The corresponding anions and cations possess high mobilities, being that the molecules of water and polar organic compounds (hydrocarbon string of short lengths) can enter and leave the flexible polyanion structure [50,51, 52]. Fast migration (diffusion) of protons for the majority of protons happens at approximately $230^{\circ} \mathrm{C}$ [1]. The protonic conductivities of PWA in solid state can be correlate with their acid-base features, which mechanisms are based on the proton jumps and the oscillation amplitudes of oxygen atoms in their three-dimensional structures, as was reported by Yaroslavtsev et al [51]. The heteropolyanion (e.g. PWA) constitute very strong Brønsted acids [50-52]. The intermolecular proton transfer pathway can be based on the simultaneous presence of donors and acceptors in proton transfer reactions. For the intermolecular pathway in PEM (between adjacent PWA molecules), due to the strong interactions between the silica surface and the PWA molecules (probably the most predominant), the corresponding distances between the latter will undergo small modifications during proton transport [15]. The intermolecular protons transfer can be supported by the study Marcos de Oliveira, Jr. et al that mentioned that around the 12-phosphotungstic acid $\left(\mathrm{H}_{3} \mathrm{PW}_{12} \mathrm{O}_{40}\right.$, PWA) there are hydration environments dependent of the temperature [53]. Also, ${ }^{1} \mathrm{H}$ NMR confirmed the existence of a balance of hydrated species $\mathrm{H}_{5} \mathrm{O}_{2}^{+} \leftrightarrow \mathrm{H}_{3} \mathrm{O}^{+}+\mathrm{H}_{2} \mathrm{O} \leftrightarrow \mathrm{H}^{+}+2 \mathrm{H}_{2} \mathrm{O}$, indicating high mobilities for them, as also detecting mobile interstitial water in clusters $\left(\mathrm{H}_{2} \mathrm{O}\right)_{n}$ [53]. The effect of water on proton conductivity of PWA is one of the most key features in PEMFCs. The presence of PWA (very strong acid) significantly increases the positive charge accumulated on silica surface. In these materials, the protons conductivity depends on the distances among PWA clusters, which in turn depends of the weight percentage of PWA as reported by Zhou et al [15]. As reported by these authors for PEMFCs, if the distance among the neighbours PWA molecules is less than $17.0 \AA$ then the intermolecular proton transfer is more predominant than intramolecular proton transfer, possibly due to steric impediments and charge effects. EXAFS studies of PWA immobilized in ormosil corresponding to the first and second coordination spheres of the Tungsten absorption edge $\mathrm{L}_{\text {III }}\left(\mathrm{W}-\mathrm{L}_{\mathrm{III}}\right)$ shown interatomic distances at the intervals $1.26 \AA-2.10 \AA$ and $2.35 \AA-4.45 \AA$ respectively [40]. Among these distances there are ones that do not correspond to PWA, so indicating the presence of other atoms (isolated or in combination) different from those present in the structure $\left[\mathrm{PW}_{12} \mathrm{O}_{40}\right]^{3-}$ as Tungsten $(\mathrm{W})$, Phosphorus $(\mathrm{P})$ and Oxygen $(\mathrm{O})$ [40]. In the study reported by Kelen Aguiar et al, Wide angle X-ray scattering (WAXS) measurements for the PDMSUr-PWA films shown some diffraction halos, nonetheless they also presented crystalline peaks on top surface (APTES and PWA induce crystallization) [11]. For these materials, the WAXS results shown three peaks, centred at around $2 \Theta=7^{\circ}, 18^{\circ}$, and $29^{\circ}$ corresponding to the d-spacings (inter-unit distances) of $12.6 \AA$ (semi-crystalline structure), $4.9 \AA$ and $3.08 \AA$ (both related to amorphous polyhedral oligomeric silsesquioxane POSS cage structures) respectively ${ }^{9}$. PDMS diffraction patterns present two halos at around $12.8^{\circ}$ and $22.6^{\circ}$, also presented in WAXS experiments for PDMSUr ${ }^{11}$, which indicate that their microstructure is amorphous [13]. If there are continuity of domains (semi-crystalline/amorphous) could attain the conditions in order to be regarded as pathways of conduction in the protons network [1]. The presence of PWA (negative charge) significantly increases the positive charge accumulated on silica surface and channels (correlated also to the formation of functional groups) through electrostatic interactions [14-15]. The knowledge of structure of PWAs and their corresponding protonic conductivity induced in hybrid material domains (e.g. 
through channels) constitute paramount parameters in order to understanding these transfer processes [1]. One model for the distribution of PWA channels in PDMSUr-PWA films was presented in the study reported by Elguera et al [26]. FEG-SEM images corresponding to the thickness of the PDMSUr-PWA films revealed that between 35 to 55\% PWA of content a significant change in their morphology occur $[9,12]$. HPAs can performed as crosslinkers and nano-enhancers (e.g. of the clusters), being able of increase the elastic modulus of polymer that acts as matrix (in this case PDMSUr) hundreds of times [1, 12]. In PEMs based on PWA-meso-silica nanocomposites the average distances between PWA particles are function of PWA content. The morphology of nanochannels distribution (formed by PWA-polymer hybrid domains) and the networks (hydrogen bonds) among HPAs and polar groups $\left(-\mathrm{O}-,-\mathrm{O}=\mathrm{S}=\mathrm{O}-,-\mathrm{SO}_{3} \mathrm{H},-\mathrm{OH}\right)$ existent determine the proton conductivity in PEMs [1]. From TEM results of PEMFCs based on silica and PWA, for $20 \mathrm{wt} / \mathrm{wt} \%$ PWA and $80 \mathrm{wt} / \mathrm{wt} \%$ PWA contents, the corresponding distances are in the ranges 1-10 nm and 1.0-1.5 nm respectively. FEG-SEM images correspondent of PDMSUr-PWA films containing $45 \mathrm{wt} / \mathrm{wt} \%$ and $55 \mathrm{wt} / \mathrm{wt} \%$ has shown distances (approximately) between PWA agglomerates at the ranges $2-13 \mu \mathrm{m}$ and $1-4 \mu \mathrm{m}$ respectively [26]. TEM characterization would be necessary in order to compare the distances between PWA nanoparticles (with those mentioned above), besides also for the knowledge of the morphologies and distributions of PWA nanoparticles agglomerates at scale of nanometers in PDMSUr-PWA films [15]. The high concentrations of PWA may affect the morphology and proton transport of the PEMFCs [1]. Insofar the PWA contents increase, the corresponding distances between PWAs decrease, leading to an enhancement of proton conductivities. According to the model proposed by Zhou et al, the proton conductivity remains unchanged when the PWA content on meso-silica is above $67 \mathrm{wt} / \mathrm{wt} \%$ [15]. According to the model proposed by Elguera et al for the PWA distribution at PDMSUr-PWA films, for PWA contents $>50 \% \mathrm{wt} / \mathrm{wt}$ the intermolecular proton transfer pathway would be predominant, due to that the distance among PWA clusters are minimized and also their presence at surface, in consequence the segregation at thickness is very significant [26]. On the other hand, for PWA contents $<35 \% \mathrm{wt} / \mathrm{wt}$, the intramolecular proton transfer pathway would be predominant, and according to Elguera et al this PWA concentration level the tungsten segregation at surface of these films is prevalent, probably based on the electrostatic interactions among PWA with ORMOSIL and amines groups [26]. For these reasons, PDMSUr-PWA films can be considered as potential candidates for use as membrane fuel cells. For these reasons, PDMSUr-PWA films can be considered as potential candidates for use as membrane fuel cells.

\subsubsection{PDMSUr-PWA Films as Hydrogen/Bromine Cells}

$\mathrm{H}_{2}-\mathrm{Br}_{2}$ electrochemical system constitute one of the most efficient Fuel cells. The presence of Bromine - evidenced by XRF (from laboratory and Synchrotron) and Volumetric analyses - and also of the protons (provided by PWA, as mentioned above), can make PDMSUr-PWA films potential candidates for $\mathrm{H}_{2}-\mathrm{Br}_{2}$ Fuel cells systems. The voltages found for Hydrogen-Bromine Fuel Cells are in the range 0.96-1.18V, while for PDMSUr-PWA films the maximum values are in the range $0.98-1.25 \mathrm{~V}[10,54,55]$. Thus, these films would be suitable for PEMFCs, in addition of the contribution of electrochemical system $\mathrm{H}_{2}-\mathrm{Br}_{2}$. At the same concentration level of Bromine [0.3M], the comparison of the overall potential curves corresponding to the PDMSUr-PWA film containing 35wt/wt\% PWA, and to the Membrane Fuel Cell (MFC) found in literature, are observed similar profiles (see Section S12 at the Supplemental Material), but the film exhibits power densities slightly higher $(8-16 \%)$ than value referenced for MFC [13]. These films could be performed as $\mathrm{H}_{2}-\mathrm{Br}_{2}$ Fuel cells operating up temperatures $120^{\circ} \mathrm{C}$ approximately, take in consideration the boiling point of Hydrobromic acid mentioned above in the section 4.2.4. In order to establish which specie (s) of Bromine are present ($\mathrm{C}-\mathrm{Br}-,-\mathrm{C}-\mathrm{Br}_{2}, \mathrm{Br}_{2}, \mathrm{HBr}, \mathrm{PDMS}-\mathrm{Br}, \mathrm{PDMS}-\mathrm{Br}_{2}$, among others) in PDMSUr-PWA films is necessary referencing to the results of characterization techniques found in literature:

Ultraviolet-Visible absorption spectroscopy: From comparison the UV spectra of PDMSUr-PWA film containing $35 \% \mathrm{wt} / \mathrm{wt}$ PWA with the standards of Bromine atomic [56], bromide anion $\left(\mathrm{Br}^{-}\right)$[57], and dibromide anion $\left(\mathrm{Br}_{2}^{-}\right)$[58] at the visible light region, only the molecular ion could provide indicatives about the presence of $\mathrm{Br}_{2}$ (see Section S11 at the Supplemental Material).

Infrared absorption spectroscopy: From section 4.2.4, there are indicatives of the presence of PDMS-Br. On another hand, there is no indicatives of presence of APTES-Br, $\mathrm{HBr}$ and $\mathrm{Br}_{2}$. For alkyl halides (-C-X-bond, where $\mathrm{X}$ : $\mathrm{F}, \mathrm{Cl}, \mathrm{Br}, \mathrm{I}),-\mathrm{C}-\mathrm{X}$ vibration frequencies appear in the region $850-515 \mathrm{~cm}^{-1}$. In terminal alkyl halides, the $-\mathrm{CH}_{2}-\mathrm{X}$ group appear at range $1300-1150 \mathrm{~cm}^{-1}$. The spectrum of PDMSUr obtained by our research group show the bands corresponding to PDMS segment in the region of $800-1300 \mathrm{~cm}^{-1}[9,10]$. Absorption in the region $690-515 \mathrm{~cm}^{-1}$ corresponds to a $-\mathrm{C}-\mathrm{Br}-$ stretching vibration, but due to the instrumental limitations sometimes it is not able to be observed at IR-spectrum [59]. The interactions $-\mathrm{Br}-\mathrm{Br}$ - would not show up in an IR spectrum due to that those vibrational motions do not change the dipole moment of the molecule. However, at $319 \mathrm{~cm}^{-1}$ and $360 \mathrm{~cm}^{-1}$, can exist for non-harmonic movements corresponding to the $\mathrm{Br}_{2}$ molecule as gas and solution respectively [59]. The segment $-\mathrm{CBr}_{2}$ present vibrational frequencies (bent structure) at 595.0 and $640.5 \mathrm{~cm}^{-1} . \mathrm{Br}_{3}(\mathrm{~s})+$ present vibrational frequencies at 293 and $297 \mathrm{~cm}^{-1}$ [59]. In the case of interaction between PWA and groups that contained Bromine (there are indicatives, from SR- $\mu$ XRF maps in Figure 4 and also Section S4 at the Supplemental Material), the segment $\mathrm{PBr}_{2}$ present vibrational frequencies (bent structure) at 369.0 and $410 \mathrm{~cm}^{-1}$ [59]. Demonstrate the interaction between Bromine and Phosphorous (-Br-P-), from corresponding IR bands, indirectly give us indicatives of interactions Bromine and Tungsten, due to that molecular PWA structure keeps intact 
inside of PDMSUr-PWA films [11]. For the case of interaction between Silicon and Bromine (there are indicatives, from SR- $\mu$ XRF maps in Figure 5 and also Section S5 at the Supplemental Material), the segment ${ }^{28} \mathrm{SiBr}_{2}$ present vibrational frequencies (bent structure) at 402.6 and $399.5 \mathrm{~cm}^{-1}$ [59]. Interactions between Bromine and Oxygen (bent structure) present vibrational frequencies at and 504 and 587 $\mathrm{cm}^{-1}$ for $-\mathrm{Br}-\mathrm{O}-\mathrm{Br}-(\mathrm{sol}) ; 865$ and $375 \mathrm{~cm}^{-1}$ for $(-\mathrm{O}-\mathrm{Br}-\mathrm{O}-)^{+}$; 710 and $320 \mathrm{~cm}^{-1}$ for (-O-Br-O-)-; $1484.0 \mathrm{~cm}^{-1}$ for $-\mathrm{O}-\mathrm{O}-$ $\mathrm{Br} ; 3589 \mathrm{~cm}^{-1}, 1164 \mathrm{~cm}^{-1}$, and $626 \mathrm{~cm}^{-1}$ for $\mathrm{H}-\mathrm{O}-\mathrm{Br} ; 805$, 810,790 , and $418 \mathrm{~cm}^{-1}$ for $\left[\mathrm{BrO}_{3}\right] ; 1828,757,512$ and 425 $\mathrm{cm}^{-1}$ for $\mathrm{OCBr}_{2}$ [59]. Features in the ranges $750-500 \mathrm{~cm}^{-1}$ and $500-250 \mathrm{~cm}^{-1}$ are found in spectra of PDMSUr and precursors (CCPDMS) $[9,11]$. Referent to the Hydrobromic acid (HBr), the corresponding range of bands is $2700-2650 \mathrm{~cm}^{-1}$, which presence cannot be evidenced. Nonetheless, at 1038 and 1420 $\mathrm{cm}^{-1}$ correspond to interactions $\mathrm{Br}-\mathrm{H}-\mathrm{Br}[59,60]$. FTIR spectra of PWA show very strong vibrational bands in the region of $700-1100 \mathrm{~cm}^{-1}$. It is clear that pure PWA crystal exhibits four characteristic bands, such as $1080 \mathrm{~cm}^{-1}(v \mathrm{P}-\mathrm{O})$, $981 \mathrm{~cm}^{-1}(v \mathrm{~W}-\mathrm{Od}), 889 \mathrm{~cm}^{-1}(v \mathrm{~W}-\mathrm{Ob}-\mathrm{W})$, and $802 \mathrm{~cm}^{-1}(v$ W-Oc-W) [61].

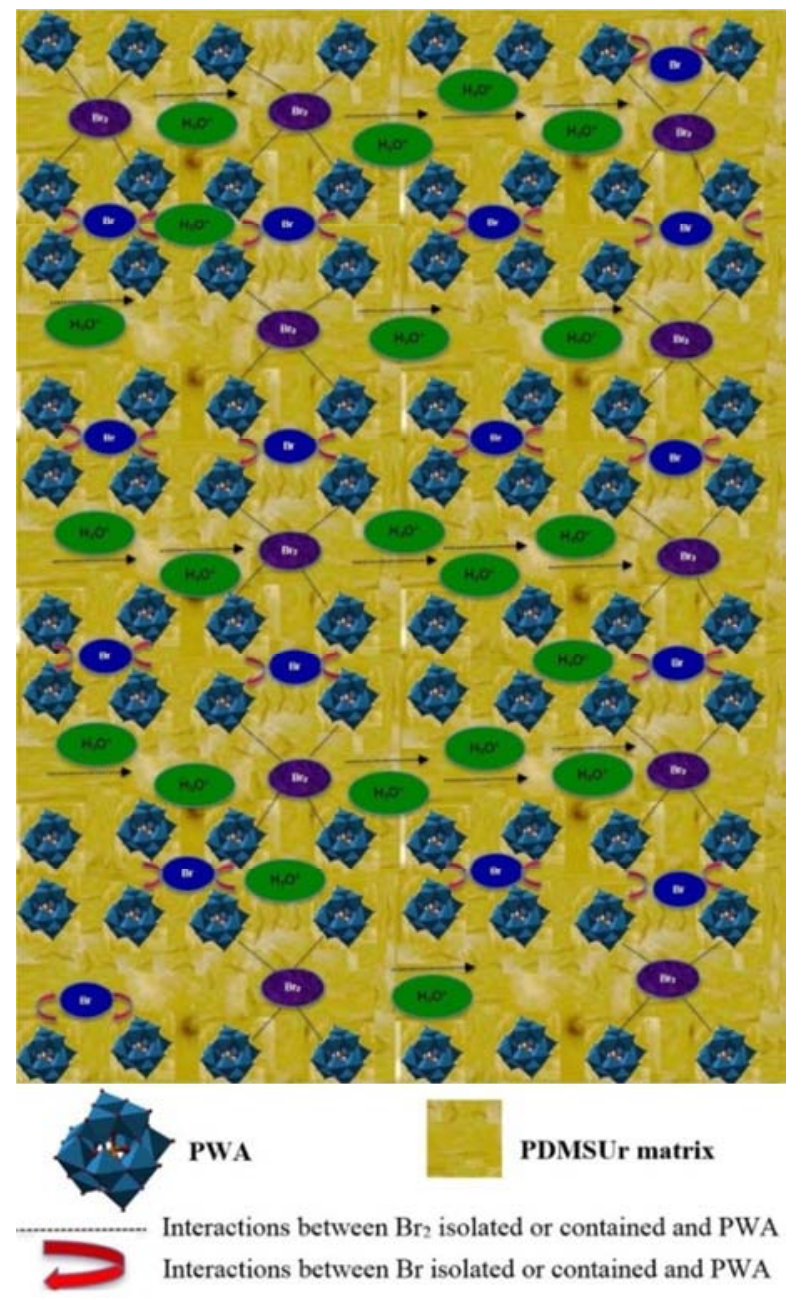

Figure 7. Representation of the possible structure of PDMSUr-PWA films, considering Bromine species distribution. The size of the compounds is out of proportion for mere illustrative effect.
Mass Spectrometry: from the revision of MALDI-TOF-MS spectra of PDMSUr matrix [9], we have indicatives of the possible presence of Bromine species (considering their corresponding isotopes ${ }^{79} \mathrm{Br}$ and ${ }^{81} \mathrm{Br}$ ) of $\mathrm{Br}, \mathrm{Br}_{2}$, and $\mathrm{HBr}$ (see Table S4 Section S11 at the Supplemental Material).

EXAFS and XRD: EXAFS studies of Bromine are necessary in order to estimate their corresponding interatomic distances with Tungsten, as also which of their coordination spheres would be the closest to Br in PDMSUr-PWA films. As an estimative, from EXAFS studies of PWA clusters hosted in ormosil membranes was inferred that there are distances non-pertaining to the Keggin structure of PWA [40]. For the first and second coordination spheres of Tungsten the corresponding interatomic distances $-\mathrm{W}-\mathrm{O}-$ are in the ranges $1.26-2.10 \AA$ and $2.35-4.45 \AA$ respectively. According to the literature, the corresponding interatomic distances of $-\mathrm{Br}-\mathrm{Br}-$ in organic crystal units obtained from X-ray diffraction (XRD) are in the range 2.436-2.705 $\AA$. Thus, there would be some possibility of interaction of molecular Bromine $\left(\mathrm{Br}_{2}\right)$ and Tungsten at the second coordination sphere of this last element. The average interatomic distances $-\mathrm{W}-\mathrm{Br}-$ obtained by XRD in the clusters of Bromine and Tungsten compounds as $\left[\mathrm{W}_{6} \mathrm{Br}_{14}\right]$ and $\mathrm{Na}\left[\mathrm{W}_{6} \mathrm{OBr}_{18}\right]$ are in the ranges 2.569-2.608 $\AA$ and 2.577-2.634 $\AA$ [62] respectively.

SR- $\mu$ XRF: from the corresponding maps SR- $\mu$ XRF of $\mathrm{Br}-\mathrm{K}_{\alpha}+\mathrm{W}-\mathrm{L}_{\alpha}$ lines (Figure 4), and $\mathrm{Br}-\mathrm{K}_{\beta}+\mathrm{W}-\mathrm{M}_{\alpha}$ lines (see also Section S4 at the Supplemental Material), we could infer about interactions external and internal respectively between the distributions of electronic densities of $\mathrm{Br}$ and $\mathrm{W}$. The external and internal distributions patterns are opposite between them, being the proximity between these elements (common regions) more significant for internal shells. In external distribution patterns the presence of isolated Bromine regions is significant, from which could indicate the existence Van der Waals interactions (or loosely bonds) instead of covalent chemical bonds with Tungsten. Taking in consideration EXAFS results mentioned above, the chemical interactions of those elements would be possible from second coordination shell of Tungsten mainly. Thus, the hypothesis considered is that inside of PWA Keggin structure (at the first coordination sphere of Tungsten) could contain some atoms of $\mathrm{Br}$ (in isolated form or contained in short-chains of hydrocarbons), which are entering or exiting of this structure, interacting via electrostatic forces, supported in the model of proposed by Kozhevnikov [50]. At outside surrounds of the of Keggin structure of PWA, at the second coordination sphere of Tungsten $(2.35-4.45 \AA)$ [40], would be viable the interactions with Bromine, as molecular form $\left(\mathrm{Br}_{2}\right)$ and/or linked to medium and/or long-chains of hydrocarbons, via forces electrostatics and/or Van der Waals. These last forces are significant for polymers/copolymers, where the contact surface among the molecule clusters is significant. Van der Waals radius for Bromine is $1.85 \AA$ [63]. This value is in the range of interatomic distances corresponding to the first

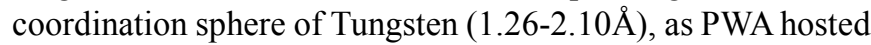
in ormosil [40], reason for what there would be possible the presence of Van der Waals forces among molecules or atoms 
of $\mathrm{Br}$ and $\mathrm{W}$ inside of Keggin structure. At higher coordination spheres of Tungsten increases the possibility of Bromine interactions with other elements, thus, diminishing the respective spatial correlation patterns (coverture) between $\mathrm{Br}$ and $\mathrm{W}$, as also increasing their corresponding interatomic distances. Based on that was discussed, Figure 7 depicts the hypothesis of the structure of PDMSUr-PWA films, considering the different Bromine species (containing $\mathrm{Br}$ or $\mathrm{Br}_{2}$ ) that can interact with PWA clusters.

Figure 8 shows the models of distribution of Tungsten and Bromine in PDMSUr-PWA films as function of PWA content:

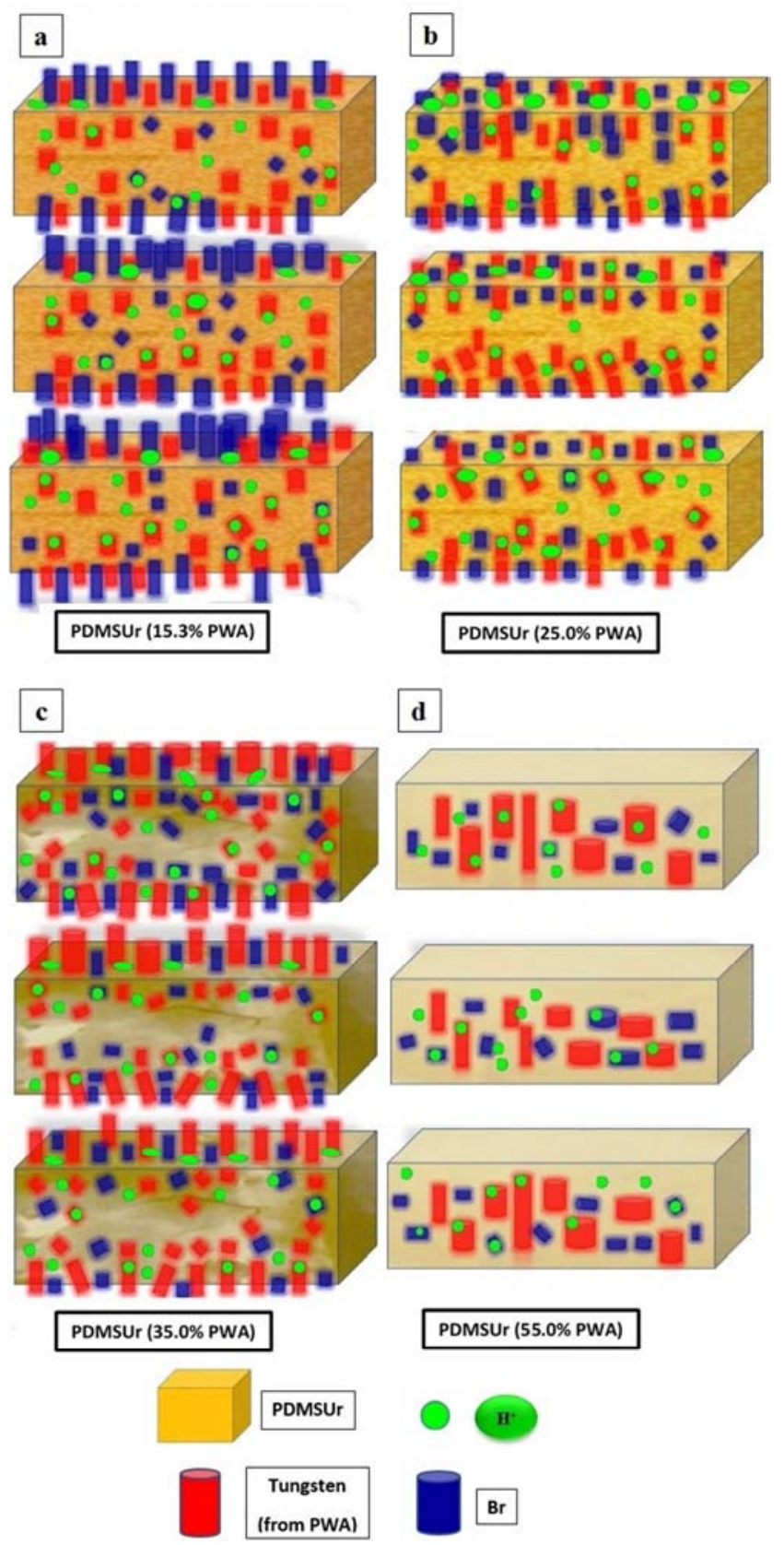

Figure 8. Models of Batteries based on Tungsten (as PWA) and Bromine distributions for PDMSUr-PWA films as function of PWA content: a) $15.3 \% \mathrm{wt} / \mathrm{wt}$, b) $25 \% \mathrm{wt} / \mathrm{wt}$, c) $35 \% \mathrm{wt} / \mathrm{wt}$, d) $55 \% \mathrm{wt} / \mathrm{wt}$.

Below is shown the description of these systems for application as Fuel Cells, based on the Tungsten (as PWA) and Bromine distributions in the PDMSUr-PWA films.

A. At $15 \%$ PWA: For this configuration, at surface there is highly presence of non-polar forces (weak intermolecular interactions) and lightly presence of polar forces (Coulomb interactions, interactions among permanent dipoles, and ones between permanent and induced dipoles) [9-12, 40]. For this PWA content, it is possible establish a set of films can be connected in a series configuration for use as PEMFC, in order to take advantage of that the main PWA distribution is localized at thickness of these films mainly. For use as $\mathrm{H}_{2}-\mathrm{Br}_{2}$ cells, the corresponding films can be connected in a parallel configuration, taking in consideration that Bromine are localized at surface of these films mainly.

B. At 25\% PWA: For this system, at the surface there is lightly presence of non-polar and polar forces. For this PWA content, it is possible establish a set of films can be connected in a series configuration for use as PEMFC as well as $\mathrm{H}_{2}-\mathrm{Br}_{2}$ cells, taking in consideration that for Tungsten their distribution is share between the surface and thickness, while that for Bromine their corresponding distribution is localized at thickness of these films mainly.

C. At 35\% PWA: For this system, at the surface would predominate highly the non-polar and polar forces. For this PWA content, it is possible establish a set of films can be connected in a parallel configuration for use as PEMFC, taking in consideration that for Tungsten (as PWA) their distribution is localized mainly at surface of these films. For use as $\mathrm{H}_{2}-\mathrm{Br}_{2}$ cells, the films can be connected in a series configuration, taking in consideration that their corresponding distribution is localized between the surface and thickness.

D. At 55\% PWA: For this system, at the surface there is almost non-presence of non-polar and polar forces. For this PWA content, it is possible establish a set of films that can be connected in a series configuration for use as PEMFC as well as $\mathrm{H}_{2}-\mathrm{Br}_{2}$ cells, taking in consideration that for Tungsten and Bromine their corresponding distributions are localized at thickness of these films mainly.

\section{Conclusions}

This study based on multiple analyses (EDXRF, WDXRF, SR- $\mu$ XRF and Volumetric titration) has evidenced the presence of Bromine $(\mathrm{Br})$ in the complex system that constitute PDMSUr-PWA films. SR- $\mu$ XRF has proven to be a very useful method of analysis in order to monitor the Bromine distributions in the PDMSUr-PWA films. SR- $\mu$ XRF maps of spatial correlation of common regions Bromine + Tungsten (at the ranges [1-8.3] \%PWA and [35-55] \%PWA) and Bromine + Silicon (at the ranges [1-15.3] \%PWA and [35-50] \%PWA) shown there are heterogeneous distribution patterns mainly. Besides of this these common regions constitute indicatives the possibility of inter-elemental interactions between the corresponding 
pairs of elements mentioned above. More in depth studies are necessary in order to know if the Bromine is trapped in the three-dimensional of silicates and phosphotungstates network as atomic, ionic and/or molecular form. From EDXRF, WDXRF, SR- $\mu$ XRF results, it can conclude about the inverse relationship between the of Bromine and Tungsten intensities. There is segregation of Bromine at surface and through the thickness of PDMSUr-PWA films, which is function of PWA concentration. At incident angles range $\left[0^{\circ}-0.50^{\circ}\right]$ of the $\mathrm{X}$-ray beam there are indicatives of segregation of Bromine at the top surface of these films. At $25 \%$ PWA, there is significant segregation of this chemical element through the thickness, being even more at 55\% PWA. The presence of Bromine in PDMSUr-PWA films can be correlated with their adhesive, thermal-insulator and anti-corrosive properties. The films containing $1 \%, 35 \%$, $40-50 \%$ PWA are candidates as anticorrosive coatings and as inert materials under the presence of polar chemical reagents, based on the significant Bromine presence at surface. The films containing $25 \%$ and $55 \%$ PWA would be suitable for thermal insulators, based on the significant Bromine presence at thickness. PDMSUr-PWA films can constitute systems for the storage of energy based on the synergy of PEMFCs and also of $\mathrm{H}_{2}-\mathrm{Br}_{2}$ multiple micro-fuel cells. Nonetheless, more in-depth studies are necessary in order to characterize the Bromine species present (e.g. High-resolution Infrared and Raman spectroscopies), as also their local chemical and electrochemical environment (EXAFS and Voltammetry/Potentiometric Titration respectively).

\section{Acknowledgements}

The author thanks to the São Paulo Research Foundation (FAPESP) by the research grants (2011/08120-0, 2011/06019-0 and 2013/05279-3) and to the CNPq Brazilian agency by the financial support (research grants 141880/2011-2 and 160515/2011-4); to the Dr. Carlos Perez for his help at the XRF measurements done at Brazilian Synchrotron Light Source (LNLS); to the CNPEM-LNLS facilities for SR-GIXRF and SR- $\mu$ XRF measurements (proposals number: XAFS1 14254 and XAFS1 14257 respectively). We also extend our gratitude to Dra. Márcia A. Rizzutto for the EDXRF measurements, with the Amptek portable spectrometer, at Institute of Physics of the University of São Paulo (IF-USP); to Dr. Vera Luzia Salvador, Dr. Ivone Sato and Dr. Marcos Scapin for the WDXRF measurements, with the Rigaku RIX3000 spectrometer, at the Laboratory of X-ray Fluorescence (XRF) of the Centro de Química e Meio Ambiente (CQMA) from Nuclear and Energetic Research Institute of São Paulo-SP-Brazil (IPEN/CNEN-SP); and to the Analytical Center of the Institute of Chemistry from the University of São Paulo (CA-IQ-USP). Finally, the author thanks to Dr. Prof. Wagner Polito of the Institute of Chemistry of São Carlos, University of São Paulo, São Carlos-SP-Brazil (IQSC-USP) for his advices; and to the Inorganic Hybrid Materials Chemistry Group (GQMATHI-IQSC-USP).

\section{References}

[1] L. Zhai, H. Li. "Polyoxometalate-Polymer Hybrid Materials as Proton Exchange Membranes for Fuel Cell Applications". Molecules. 2019, 24 (19): 3425.

[2] K. Tsuru, S. Hayakawa, A. Osaka, and J. Ritchie. "Medical Applications of Hybrid Materials" and "Electronic and Electrochemical Applications of Hybrid Materials". In Guido Kickelbick editor. Hybrid Materials Synthesis, Characterization, and Applications. Weinheim, Germany: Wiley-VCH Verlag GmbH \& Co., 2007. Chapter 8 and Chapter 10, Pp. 323-335, and 401-402.

[3] L. Wang, Q. Ji, T. Glass, T. Ward, et al. "Synthesis and Characterization of Organosiloxane Modified Segmented Polyether Polyurethanes". Polymer. 2000. 41: 5083-5093.

[4] M. Pergal, J. Dzunuzovic, R. Poreba, D. Micic, et al. "Surface and Thermomechanical Characterization of Polyurethane Networks Based on Poly(Dimethylsiloxane) and Hyperbranched Polyester”. Exp. Polym. Lett. 2013.7 (10): 806-820.

[5] J. Cabrera, M. Ruiz, M. Fascio, N. D’Accorso, R. Mincheva, P. Dubois, L. Lizarraga and R. Negri. "Increased Surface Roughness in Polydimethylsiloxane Films by Physical and Chemical Methods". Polymers 2017.9 (331): 1-15.

[6] M. Planes, C. Le Coz, A. Soum, S. Carlotti, V. Rejsek-Riba, S. Lewandowski, S. Remaury, S Solé. "Polydimethylsiloxane/Additive Systems for Thermal and Ultraviolet Stability in Geostationary Environment". Journal of Spacecraft and Rockets. 2016. 53 (6): 1-6.

[7] E. Maaskant, K. Tempelman, N. Benes. "Hyper-cross-linked thin polydimethylsiloxane films". European Polymer Journal, 2018. 109: 214-221.

[8] J. Vega, S. Madrigal, J. Martínez. "Thermoplastic Polyurethanes-Fumed Silica Composites: Influence of $\mathrm{NCO} / \mathrm{OH}$ in the Study of Thermal and Rheological Properties and Morphological Characteristics". In: A. Zaki, E. Sonbati editors. ThermoplasticComposite Materials. Croatia: Intech, 2012. Pp. 11-25.

[9] K. Rossi Flores de Aguiar. Síntese de Hidroxiuretana-Poli(dimetilsiloxano) com Diferentes Terminações de Cadeia via Fixação de $\mathrm{CO}_{2}$ : Síntese, Caracterizações e Aplicações. [Doctor of Science in Analytical and Inorganic Chemistry, Thesis]. Instituto de Química de São Carlos. São Carlos, São Paulo-Brasil: Universidade de São Paulo (IQSC-USP), 2015. Unpublished.

[10] K. R. Aguiar, V. G. Santos, M. Eberlin, K. Rischka, et al. "Efficient Greensynthesis of Bis(Cyclic Carbonate) Poly(Dimethylsiloxane) Derivative Using $\mathrm{CO}_{2}$ Addition: A Novel Precursor for Synthesis of Urethanes". RSC Adv. 2014. 4 (46): 24334-24343.

[11] K. M. F. Rossi de Aguiar, E. P. Ferreira-Neto, S. Blunk, J. F. Schneider, et al. "Hybrid Urethanesil Coatings for Inorganic Surfaces Produced by Isocyanate-Free and Sol-Gel Routes: Synthesis and Characterization". RSC Adv. 2016. 6 (23): 19160-19172.

[12] K. M. F. Rossi de Aguiar, U. Specht, J. Maass, D. Salz, C. Picon, M. Noeske, K. Rischka and U. P. Rodrigues-Filho. "Surface modification by physical treatments on biomedical grade metals to improve adhesion for bonding hybrid non-isocyanate urethanes". RSC Adv. 2016. 6 (53): 47203-47211. 
[13] P. Ferreira, A. Carvalho, T. R. Correia, B. P. Antunes, I. J. Correia, P. Alves. "Functionalization of polydimethylsiloxane membranes to be used in the production of voice prostheses". Science and Technology of Advanced Materials. 2013. 14 (5): 055006 .

[14] Y. Liu, Y. Lu, A. Haragirimana, I. Buregeya, N. Li, Z. Hu, S. Chen. "Immobilized phosphotungstic acid for the construction of proton exchange nanocomposite membranes with excellent stability and fuel cell performance". International Journal of Hydrogen Energy. 2020. 45 (35): 17782-17794.

[15] Y. Zhou, J. Yang, H. Su, J. Zeng, S. Ping-Jiang, W. Goddard. "Insight into Proton Transfer in Phosphotungstic Acid Functionalized Mesoporous Silica-Based Proton Exchange Membrane Fuel Cells". Journal of the American Chemical Society. 2014. 136 (13): 4954-4964.

[16] K. Saadi, P. Nanikashvili, Z. Tatus-Portnoy, S. Hardisty, V. Shokhen, M. Zysler, D. Zitoun. "Crossover-Tolerant Coated Platinum Catalysts in Hydrogen/Bromine Redox Flow Battery". Journal of Power Sources. 2019. 422: 84-91.

[17] K. Höhne, G. Starbeck. Hydrogen/Bromine Cell. U.S. Patent: 4,520,081. Filed: 1983. Issued 1985.

[18] Novel bromine battery: Small-scale demo, large-scale promise. Spring 2014 issue of Energy Futures. https://energy.mit.edu/wp-content/uploads/2016/06/MITEI-En ergy-Futures-Spring-2014.pdf [accessed 28 July 2020].

[19] R. Savinell, S. Fritts. Theoretical and Experimental Flow Cell Studies of a Hydrogen-Bromine Fuel Cell, Part 1. [Chemical Engineering M.S. Thesis]. University of Akron, Akron, Ohio, United States, 1986. Pp. 1-8, 16-24.

[20] H. Kreutzer, V. Yarlagadda, T. Van Nguyen. "Performance Evaluation of a Regenerative Hydrogen-Bromine Fuel Cell". Journal of The Electrochemical Society. 2012. 159 (7): F331-F337.

[21] T. Van Nguyen, V. Yarlagadda, G. Lin, G. Weng, C. Ying, V. Li, $\mathrm{K}$ Chan. "Comparison of Acid and Alkaline Hydrogen-Bromine Fuel Cell Systems". ECS TransactionsElectrochemical Society. 2014. 58 (37): 29-35.

[22] T. Nguyen, V. Yarlagadda, D. Konwar, K. Chan. "359395 Alkaline-Based Hydrogen-Bromine Fuel Cell”. 2014. AIChE Annual Meeting.

https://www.aiche.org/conferences/aiche-annual-meeting/2014 /proceeding/paper/304d-alkaline-based-hydrogen-bromine-fue 1-cell-1 [accessed 28 July 2020].

[23] W. Glass, G. Boyle. "Performance of Hydrogen-Bromine Fuel Cells". In: Fuel Cell Systems, George J. Young, Henry R. Linden. Advances in Chemistry-American Chemical Society. 1969. 47 (15): 203-220.

[24] Elestor Electricity Storage. "The choice for hydrogen and bromine".

https://www.elestor.nl/technology-the-elestor-solution/ [accessed 28 July 2020].

[25] Energy storage for the grid \& Transportation. Introduction to Hydrogen/Bromine regenerative fuel cells. LAS 493 Special Topics in Energy and Sustainability. https://las493energy.wordpress.com/2017/09/25/introduction-t o-hydrogenbromine-regenerative-fuel-cells/ [accessed 28 July 2020].

[26] O. Elguera, K. Rossi de Aguiar, C. Zamboni, W. Polito, U. P.
Rodrigues-Filho. "Qualitative and Semiquantitative Determination of the Atomic and Molecular Tungsten Distributions in Hybrid HydroxyurethanesPoly(dimethylsiloxane) Films Containing Phosphotungstates ([PW12O40]3-)”. Applied Spectroscopy. 2020. 0 (0) 1-15.

[27] C. Furl, C. Mathieu, T. Roberts. Washington State Department of Ecology. Evaluation of XRF as a Screening Tool for Metals and PBDEs in Children's Products and Consumer Goods. United States of America, 2012. Pp. 30-35.

[28] A. Takeda, S. Yamasaki, H. Tsukada, Y. Takaku, S. Hisamatsu, N. Tsuchiya. "Determination of total contents of bromine, iodine and several trace elements in soil by polarizing energy dispersive X-ray fluorescence spectrometry". Journal Soil Science and Plant Nutrition/Soil Chemistry and Soil Mineralogy. 2011.57 (1): 19-28.

[29] M. Ziegler, T. Jilbert, G. De Lange, L. Lourens, G. Reichart. "Bromine counts from XRF scanning as an estimate of the marine organic carbon content of sediment cores". Geochemistry, Geophysics, Geosystems. 2008. 9 (5).

[30] A. Jinsung, J. Hyeyeon, B. Jo-Ri, Y. Hye-On, S. Jungju. "Feasibility of wavelength dispersive X-ray fluorescence spectrometry for a simplified analysis of bromine in water samples with the aid of a strong anion exchange disk". Spectrochimica Acta. Part B, Atomic Spectroscopy. 2014. 91: 1-4.

[31] Y. Tateishi, T. Hashimoto, K. Ushiyama, N. Sakai, I. Baba, T. Nagayama. "Simple analytical method of bromine in fruits and grain products with wavelength dispersive X-ray fluorescence spectrometer". Journal of the Food Hygienic Society of Japan (Shokuhin Eiseigaku Zasshi). 2010. 51 (2): 53-7.

[32] G. Pashkova, T. Aisueva, A. Finkelshtein, E. Ivanov, A. Shchetnikov. "Analytical approaches for determination of bromine in sediment core samples by X-ray fluorescence spectrometry". Talanta. 2016. 160: 375-380.

[33] I. Mantouvalou, T. Wolff, O. Hahn, I. Rabin, L. Lühl, M. Pagels, W. Malzer, B. Kanngiesser. "3D Micro-XRF for Cultural Heritage Objects: New Analysis Strategies for the Investigation of the Dead Sea Scrolls". Analytical Chemistry. 2011.83 (16): $6308-6315$.

[34] A. Leri, S. Myneni. "Natural organobromine in terrestrial ecosystems". Geochimica et Cosmochimica Acta. 2012. 77: $1-10$.

[35] G. Suzuk, A. Kida, S. Sakai, H. Takigami. "Existence State of Bromine as an Indicator of the Source of Brominated Flame Retardants in Indoor Dust". Environ. Sci. Technol. 2009. 43 (5): $1437-1442$.

[36] S. Kutterolf, T. Hansteen, A. Freundt, H. Wehrmann, K Appel, K. Krüger, W. Pérez. "Bromine and chlorine emissions from Plinian eruptions along the Central American Volcanic Arc: From source to atmosphere". Earth and Planetary Science Letters. 2015. 429 234-246.

[37] C. Pérez, M. Radtke, H. Sánchez, H. Tolentino, et al. "Synchrotron Radiation X-ray Fluorescence at the LNLS: Beamline Instrumentation and Experiments". X-ray Spectrom. 1999. 28 (5): 320-326.

[38] V. Solé, E. Papillon, M. Cotte, Ph. Walter, J. Susini. “A Multiplatform Code for the Analysis of Energy-Dispersive X-ray Fluorescence Spectra”. Spectrochim. Acta, Part B. 1999. 62 (1): $63-68$. 
[39] PyMca. "PyMca X-ray Fluorescence Toolkit Home Page". http://pymca.sourceforge.net/documentation.html. [accessed 28 July 2020$]$.

[40] O. A. Elguera Ysnaga. Métodos de Análise de Materiais Híbridos: Um Estudo Comparativo Entre Fluorescência de Raios-X Com Detecção Dispersiva em Energia Usando Fonte Tradicional e Luz Síncrotron. [Doctor of Science in Analytical and Inorganic Chemistry, Thesis]. Instituto de Química de São Carlos. São Carlos, São Paulo-Brasil: Universidade de São Paulo (IQSC-USP), 2015. Pp. 249-301. Unpublished.

[41] W. Schöniger, "Analytical Procedures for the Flask Combustion Method". In: Pergamon Press. Proceedings of the International Symposium on Microchemistry, Basle, Switzerland. Sandoz Ltd, 1958. Pp. 93-95.

[42] H. Zhao-sheng, Q. Wen-qiang, K. Cheng-you. "Synthesis and properties of triethoxysilane-terminated anionic polyurethane and its waterborne dispersions". Journal of Polymer Research. 2015. 22 (6): 111.

[43] D. Li, F. Wang, X. Yu, J. Wang, Q. Liu, P. Yang, Y. He, Y. Wang, M. Zhang. "Anticorrosion organic coating with layered double hydroxide loaded with corrosion inhibitor of tungstate". Progress in Organic Coatings. 2011.71 (3): 302-309.

[44] S. Oleinik, Y. Kuznetsov, A. Vartapetyan, "Corrosion Inhibition of Steel in Lithium Bromide Brines". Protection of Metals. 2003. 39 (1): 12-18.

[45] J, Datta, C. Bhattacharya, S. Bandyopadhyay. "Influence of Cl$1, \mathrm{Br}-1, \mathrm{NO} 3-1$ and SO4-2 ions on the corrosion behaviour of 6061 Al alloy”. Bulletin of Materials Science. 2005. 28 (3): 253-258.

[46] J. Hernandez, R. García-Alamilla, G. Sandoval-Robles, J. Melo-Banda, L. García-Serrano. "Effect of the addition of phosphotungstic acid on the thermal stability of zirconium oxide". DYNA. 2014. 81: 107-114.

[47] Q. Tu, J. Wang, R. Liu, J. He, Y. Zhang, S. Shen, J. Xu, J. Liu, M. Yuan, J. Wang. "Antifouling properties of poly(dimethylsiloxane) surfaces modified with quaternized poly (dimethylaminoethyl methacrylate)". Colloids and Surfaces B: Biointerfaces. 2013.102: 361-370.

[48] L. Zheng-hong, H. Teng-yun. "Synthesis and characterization of poly(dimethylsiloxane)-block- poly (2,2,3,3,4,4,4-heptafluorobutyl methacrylate) diblock copolymers with low surface energy prepared by atom transfer radical polymerization". Reactive and Functional Polymers. 2008. 68 (5): 931-942.

[49] https://webbook.nist.gov/cgi/cbook.cgi?ID=C10035106\&Mas $\mathrm{k}=80 \# I R-$ Spec. [accessed 28 July 2020].

[50] I. Kozhevnikov. "Catalysis by heteropoly acids and multicomponent polyoxometalates in liquid-phase reactions". Chemical Reviews. 1998. 98 (1): 171-198.
[51] A. Yaroslavtsev, D. Gorbatchev. "Proton mobility in the solid inorganic hydrates of acids and acid salts". Journal of Molecular Structure. 1997. 416 (1-3): 63-67.

[52] J. Keggin. "The structure and formula of 12-phosphotungstic acid". Proceedings of the Royal Society of London. Series A. 1934. 144 (851): 75-100.

[53] M. de Oliveira, U. P. Rodrigues-Filho, J. Schneider. "Thermal Transformations and Proton Species in 12-Phosphotungstic Acid Hexahydrate Studied by $1 \mathrm{H}$ and $31 \mathrm{P}$ Solid-State Nuclear Magnetic Resonance". The Journal of Physical Chemistry C. 2014. 118 (22): 11573-11583.

[54] M. Suss, K. Conforti, L. Gilson, C. Buie, M. Bazant. "Membraneless flow battery leveraging flow-through heterogeneous porous media for improved power density and reduced crossover". RSC Adv. 2016 (6): 100209-100213.

[55] W. Braff, M. Bazant, C. Buie. "Membrane-less hydrogen bromine flow battery". Nature Communications 2013. 4 (1): 2346 .

[56] A. Passchier, J. Christian, N. Gregory. "The ultraviolet-visible absorption spectrum of bromine between room temperature and $440^{\circ} \mathrm{C}$ ". Journal of Physical Chemistry. 1967. 71 (4): 937-942.

[57] D. Zehavi, J. Rabani. "The Oxidation of Aqueous Bromide Ions by Hydroxyl Radicals. A Pulse Radiolytic Investigation". Journal of Physical Chemistry. 1972. 76 (3): 312-319.

[58] Quantification of Bromide by APHA 4500 Method: Phenol Red Colorimetric Method https://www.perkinelmer.com/lab-solutions/resources/docs/AP P-Quantification-of-Bromide-by-APHA-4500-using-LAMBD A-465-012208A_01.pdf. [accessed 02 November 2020].

[59] K. Nakamoto. Infrared and Raman Spectra of Inorganic and Coordination Compounds Part A: Theory and Applications in Inorganic Chemistry. New Jersey: John Wiley \& Sons, 2009. Pp. 13, 155, 164, 166, 170, 172.

[60] E. Plyler. "Infrared Spectrum of Hydrobromic Acid". Journal of Research of the National Bureau of Standards-A. Physics and Chemistry. 1960. 64 (5): 377-379.

[61] W. Feng, T. Zhang, J. Liu, R. Lu, Y. Zhao, J. Yao. "Ultrasound-induced change of microstructure and photochromic properties of PAM thin films containing a polyoxometalate". Journal of Materials Research. 2003. 18 (03): 709-713. (2003).

[62] P. Abramov, A. Rogachev, M. Mikhailov, A. Virovets, E. Peresypkina, M. Sokolov, V. Fedin, "Hexanuclear chloride and bromide tungsten clusters and their derivatives". Russian Journal of Coordination Chemistry. 2014. 40 (5): 259-267.

[63] Crystal Maker® Software. "Elements, Atomic Radii and the Periodic Radii".2020. http://crystalmaker.com/support/tutorials/atomic-radii/index.ht $\mathrm{ml}$ [accessed 28 July 2020]. 